\title{
Why do CD8+T cells become indifferent to tumors: a dynamic modeling approach
}

\section{Colin Campbell ${ }^{1,+}$, Ranran Zhang ${ }^{2,+}$, Jeremy S. Haley ${ }^{3}$, Xin Liu $^{4}$, Thomas Loughran $^{4}$, Todd D. Schell $^{3}$, Réka Albert ${ }^{1}$ and Juilee Thakar ${ }^{1}$ *}

1 Department of Physics, The Pennsylvania State University, University Park, PA, USA

2 Duke-NUS Graduate Medical School Singapore, Singapore

${ }^{3}$ Department of Microbiology and Immunology, The Pennsylvania State University College of Medicine, Hershey, PA, USA

${ }^{4}$ Penn State Hershey Cancer Institute, The Pennsylvania State University, College of Medicine, Hershey, PA, USA

\section{Edited by:}

Kumar Selvarajoo, Keio University, Japan

Reviewed by:

Gabor Balazsi, The University of Texas MD Anderson Cancer Center, USA

Thomas Dandekar, University of

Wuerzburg, Germany

*Correspondence:

Juilee Thakar, Department of

Pathology, Yale University School of Medicine, 300 George Street, Suite 505, New Haven, CT 06511, USA. e-mail: juilee.thakar@yale.edu,

jthakar@phys.psu.edu

${ }^{+}$Colin Campbell and Ranran Zhang are joint first authors.
CD8+T cells have the potential to influence the outcome of cancer pathogenesis, including complete tumor eradication or selection of malignant tumor escape variants. The Simian virus 40 large T-antigen (Tag) oncoprotein promotes tumor formation in Tag-transgenic mice and also provides multiple target determinants (sites) for responding CD8+ $T$ cells in C57BL/6 $\left(H-2^{b}\right)$ mice. To understand the in vivo quantitative dynamics of CD8+ T cells after encountering Tag, we constructed a dynamic model from in vivo-generated data to simulate the interactions between Tag-expressing cells and CD8+ T cells in distinct scenarios including immunization of wild-type C57BL/6 mice and of Tag-transgenic mice that develop various tumors. In these scenarios the model successfully reproduces the dynamics of both the Tag-expressing cells and antigen-specific CD8+T cell responses. The model predicts that the tolerance of the site-specific $T$ cells is dependent on their apoptosis rates and that the net growth of CD8+ T cells is altered in transgenic mice. We experimentally validate both predictions. Our results indicate that site-specific CD8+ T cells have tissue-specific apoptosis rates affecting their tolerance to the tumor antigen. Moreover, the model highlights differences in apoptosis rates that contribute to compromised CD8+ $T$ cell responses and tumor progression, knowledge of which is essential for development of cancer immunotherapy.

Keywords: CD8+ T cells, T-antigen, tumor, dynamic model, apoptosis and proliferation rates

\section{INTRODUCTION}

Tumors are masses of host cells containing both genetically unstable cancer cells and supporting host cells, including cells of the immune system. Tumor progression causes destructive pathogenesis within the host and ultimately death. Tumor antigens, particularly those that are unique to the tumor, can elicit an adaptive immune response (Qin and Blankenstein, 2000; Patel and Chiplunkar, 2009; Xu et al., 2009; Behboudi et al., 2010). In particular, $\mathrm{CD} 8+\mathrm{T}$ cells $\left(\mathrm{T}_{\mathrm{CD} 8} \mathrm{~s}\right)$ can eliminate continuously arising nascent transformed cells, inhibit carcinogenesis, and maintain cellular homeostasis under normal conditions; this process is known as immunosurveillance (Dunn et al., 2002; Schreiber et al., 2004). Tumors, nevertheless, can escape immunosurveillance through both antigenic loss and the promotion of immunosuppression, which leads to their progression. The immune response to cancer is often studied either by tumor implantation or by inducing autochthonous tumor formation in specific tissues in mice. Tumor development can be induced in transgenic mice by expressing oncoproteins under tissue-specific promoters. Transgenic mice which develop autochthonous tumors are especially interesting since the tumor antigens are often self antigens derived from non-mutated cellular proteins and tumor formation occurs over an extended period of time, reproducing some of the immunological roadblocks which limit effective immunotherapy.
Dynamic models of tumor-immune interactions have provided insights into the processes leading to immune response failure during tumor progression. Such models have been applied to study the effect of immunotherapeutic approaches (Day et al., 2006; Castiglione and Piccoli, 2007; Kirschner and Tsygvintsev, 2009) and to characterize the various stages of the immune response to infection and cancer, with particular focus on $\mathrm{T}_{\mathrm{CD} 8} \mathrm{~s}$ (De Boer et al., 2003; Bocharov et al., 2004; Antia et al., 2005; de Pillis et al., 2005). These models highlight the importance of a variety of features of the immune response to tumors, including the density of tumor antigen, the duration of the interaction between MHCI-peptide complexes and the T cell receptor (TCR), $\mathrm{T}_{\mathrm{CD} 8}$ activation rates, immunological memory, and recruitment of precursor cells. Our study provides a unique perspective relative to previous studies, in that we focus on a comparative analysis of $\mathrm{T}$ cell responses in tumor-bearing versus wild-type (WT) mice.

The Simian virus 40 (SV40) large T-antigen (Tag) is a potent virus-encoded oncoprotein that can transform a variety of cell types (Ahuja et al., 2005). The oncogenic activity of Tag stems from its ability to inactivate tumor suppressor proteins ( $\mathrm{Rb}$ and p53) as well as to initiate cell cycle progression (Butel and Lednicky, 1999). Tag can induce responses by MHC-I-restricted $T_{C D 8}$ s, as is observed for other tumor antigens. Four unique Tag determinants recognized by $\mathrm{T}_{\mathrm{CD} 8}$ s have been defined in C57BL/6 mice (sites I, 
II/III, IV, and V; Mylin et al., 2000; Tevethia and Schell, 2001). The $\mathrm{T}_{\mathrm{CD} 8}$ response to these four determinants forms a quantitative hierarchy in which site IV, for which the most T cells accumulate, is immunodominant followed by subdominant responses to sites I and II/III. The response to site V, however, is immunorecessive, as responding $\mathrm{T}_{\mathrm{CD} 8} \mathrm{~s}$ are only detected following immunization with Tag variants lacking the three dominant determinants, or after site V-specific immunization (Tanaka et al., 1989; Fu et al., 1998). The expression of Tag as a self-antigen within Tag-transgenic mice can lead to $\mathrm{T}_{\mathrm{CD} 8} \mathrm{~s}$ unresponsiveness by mechanisms promoting both central and peripheral tolerance (Tevethia and Schell, 2001).

We construct a dynamic model describing tumor progression, elimination of tumor cells, $\mathrm{T}_{\mathrm{CD} 8}$ expansion, and decay in the context of the $\mathrm{T}_{\mathrm{CD} 8}$ response to SV40 Tag. We developed this model to describe the $\mathrm{T}_{\mathrm{CD} 8}$ response in both $\mathrm{WT}$ C57BL/6 mice responding to immunization, where Tag-expressing cells are eliminated, and in mice that express Tag as a transgene, leading to the development of autochthonous tumors and $\mathrm{T}_{\mathrm{CD} 8}$ tolerance. For the purposes of this model we define tolerance as the absence of a functional $\mathrm{T}$ cell response in the presence of tumor antigen. In transgenic mice, site-specific $\mathrm{T}_{\mathrm{CD} 8} \mathrm{~s}$ become tolerant at different time points (Theobald et al., 1997; Morgan et al., 1998; Colella et al., 2000; Nugent et al., 2000; Cordaro et al., 2002; Otahal et al., 2006; Fujimura et al., 2010) and this characteristic behavior is not seen when the WT mice encounter the Tag as a foreign antigen. Thus, the model parameterized to reproduce this observation gives insights into the characteristics of $\mathrm{T}_{\mathrm{CD} 8} \mathrm{~s}$ that are changed during tumor development.

Our model quantitatively reproduces the $\mathrm{T}_{\mathrm{CD} 8}$ response to immunization with Tag-transformed cells in WT mice (Pretell et al., 1979; Mylin et al., 2000) and the qualitative behavior of the $\mathrm{T}_{\mathrm{CD} 8}$ response in mice bearing Tag-induced pancreatic tumors (Otahal et al., 2006), osteosarcoma (Schell et al., 2000), or brain tumors (Schell et al., 1999). The model reveals strong constraints on the proliferation rates and decay rates of $\mathrm{T}_{\mathrm{CD} 8} \mathrm{~s}$ during tumor formation. Additionally, the model gives insight into how the activation, proliferation, and apoptosis rates of $\mathrm{T}_{\mathrm{CD} 8} \mathrm{~s}$ impact the expansion and contraction phase during the site-specific immune response in normal mice, as well as during tissue-specific responses and development of tolerance. Our results indicate that though the inherent characteristics of the site-specific $\mathrm{T}$ cell clones are different, the overall $\mathrm{T}_{\mathrm{CD}}$ response dynamics are surprisingly similar when encountering antigen in different tissues. We predict and experimentally validate inequalities in the activation and decay rates of the $\mathrm{T}_{\mathrm{CD} 8}$ responding to unique determinants. We also theoretically predict the rate constants leading to tumor formation, the apoptosis rates of different $\mathrm{T}_{\mathrm{CD} 8}$ clones, the peaks of $\mathrm{T}_{\mathrm{CD}}$ activity in various tumor models and the mechanism of tolerance.

\section{MATERIALS AND METHODS DYNAMIC MODEL}

Our model describes the growth of tumor by modeling the Tagexpressing tumor/malignant cells $(M)$ and their removal by site I-, II/III, IV-, and V-specific $\mathrm{T}_{\mathrm{CD} 8 \mathrm{~s}}\left(T_{i}\right.$; Figure 1 ). The basic model has five ordinary differential equations and assumes that the cells form well mixed populations. Since the dynamics after tumor clearance are not considered in the current study, the memory $\mathrm{T}$ cell state is

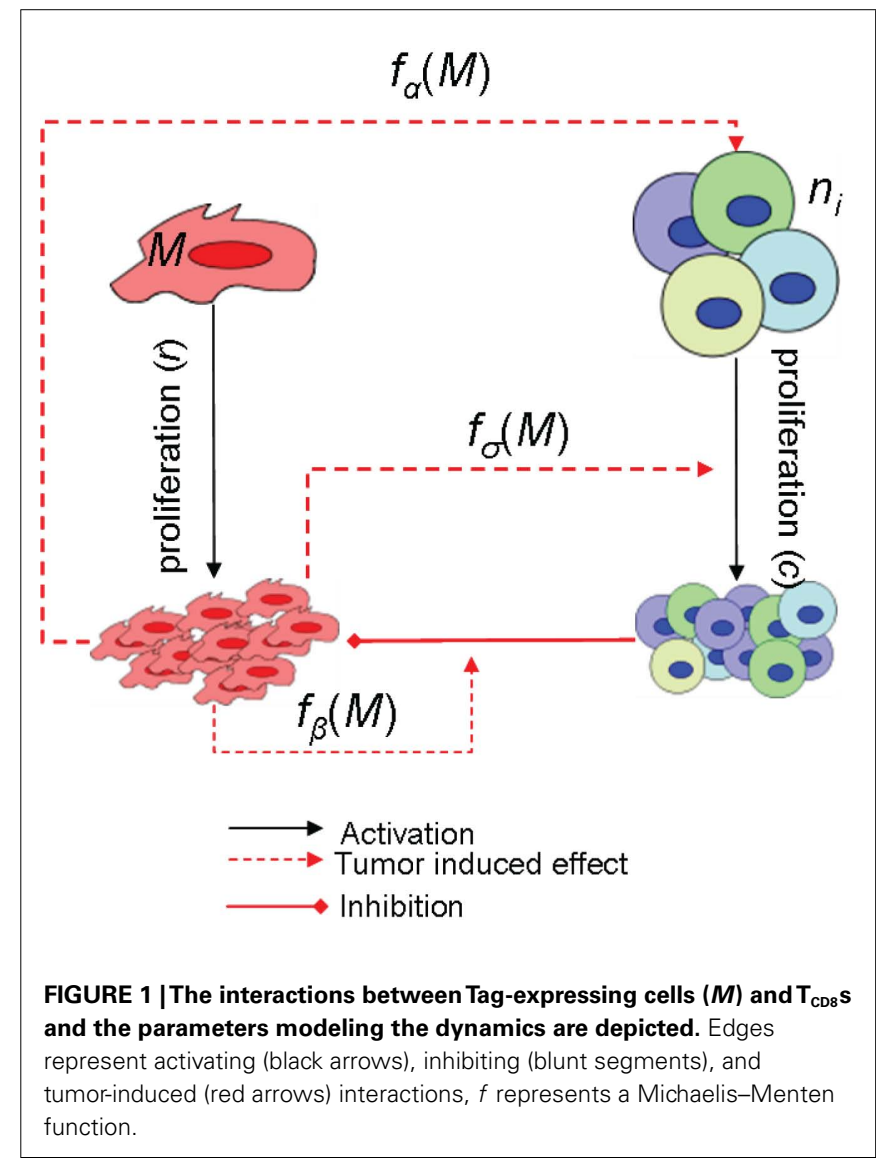

not modeled. The site-specific $\mathrm{T}_{\mathrm{CD} 8} \mathrm{~s}$ are initially activated against the tumor cells and are subsequently suppressed by the increasing tumor size in addition to their apoptosis. Tag-expressing cells exponentially proliferate at rate $r$ which was estimated from the initial growth phase of the tumors (see e.g., Mallet and De Pillis, 2006). The four site-specific $\mathrm{T}_{\mathrm{CD} 8} \mathrm{~s}$ are assumed to kill tumor cells $(M)$ at the same rate $b$; however, $b$ is modulated by a MichaelisMenten function such that the rate of killing of tumor cells stabilizes when the tumor size increases above $\beta$ (Figure A1 in Appendix).

Tag-expressing cells present four determinants I, II/III, IV, and $\mathrm{V}$ that are recognized by MHCI molecules. MHCI-peptide complexes are then recognized by TCR, which leads to the differentiation of naive cells and subsequently the recruitment of $\mathrm{T}_{\mathrm{CD} 8} \mathrm{~s}$ to the tumor site. In the model, Tag-expressing cells induce a proportion $n_{i}$ of competent site-specific $\mathrm{T}_{\mathrm{CD} 8} \mathrm{~s}$ at a rate proportional to $c$. Based on our recent experimental results (T. Schell, unpublished) a $0.3 / 1 / 4$ ratio for site $\mathrm{V} / \mathrm{I} / \mathrm{IV} \mathrm{T}_{\mathrm{CD} 8}$ activation from naïve $\mathrm{T}$ cells was used to determine $n_{i}$. Since the experimental observations could be reproduced by using the same value of the proliferation rate $c$, it was kept the same for all site-specific $\mathrm{T}_{\mathrm{CD} 8} \mathrm{~s}$. Thus $n_{i} c$ represents the activation rate of $\mathrm{T}_{\mathrm{CD} 8} \mathrm{~s}$ from precursor cells and $c$ represents the proliferation of $\mathrm{T}_{\mathrm{CD} 8} \mathrm{~s}$. $\mathrm{T}_{\mathrm{CD} 8} \mathrm{~s}$ undergo natural death at rate $w_{i}$ which is different for the four determinants. The immunogenicity of the determinants is decided by the site-specific activation and decay rates. Tumor cells alter the microenvironment leading to 
the suppression of the $\mathrm{T}_{\mathrm{CD} 8}$ response (Ganss and Hanahan, 1998; Gajewski et al., 2006). This suppression is modeled as a negative modulation of the proliferation and activation rates in response to a higher number of tumor cells. In the case of proliferation, the effect is modeled with a Michaelis-Menten function which sets proliferation to 0 for $M=0$ and saturates at $c$ for $M>>\sigma$. The negative modulation of activation rates is modeled in the opposite way, using a "repressive" Michaelis-Menten function: for $M<<\alpha_{i}$, activation occurs at a constant rate $n_{i}$; for $M>>\alpha_{i}$, it asymptotically approaches 0 . In the absence of spatial compartments, inhibition of the activation of new $\mathrm{T}_{\mathrm{CD} 8} \mathrm{~s}$ represents the suppression of the recruitment of the $\mathrm{T}_{\mathrm{CD} 8} \mathrm{~s}$ at the site of tumor which can occur by diffusible cytokines and chemokines produced by the tumor cells.

In Tag-transgenic mice both central (Faas et al., 1987; Schell et al., 1999; Colella et al., 2000; Zheng et al., 2002) and peripheral tolerance (Ye et al., 1994; Schell et al., 2000; Cordaro et al., 2002; Otahal et al., 2006) is observed in response to tumors. Tolerance is modeled by the absence of functional $\mathrm{T}_{\mathrm{CD} 8} \mathrm{~s}$ even in the presence of the Tag-expressing cells. In central tolerance self-reactive $\mathrm{T}$ cells are deleted during development in the thymus and there is no recruitment at the site of tumors, which can be modeled by setting the value of $n_{i}$ to 0 . During peripheral tolerance self-reactive T cells that escape to the periphery are maintained in a state of unresponsiveness or are deleted following activation. The gradual process of peripheral tolerance is simulated by the tumor-induced suppression of $\mathrm{T}_{\mathrm{CD} 8} \mathrm{~s}$ and by retraining the parameter values (explained in Section "Results").

Thus the dynamics of tumor cells $(M)$ and $\mathrm{T}_{\mathrm{CD} 8} \mathrm{~s}$ specific for site $i\left(T_{i}\right)$ are given by

$$
\begin{aligned}
\frac{d M}{d t}= & r M-\frac{M}{M+\beta} \sum_{i} b T_{i} \\
\frac{d T_{i}}{d t}= & c \frac{M}{M+\sigma}\left(n_{i}\left(1-\frac{M}{M+\alpha_{i}}\right)+T_{i}\right)-w_{i} T_{i}, \\
& \quad \mathrm{i} \in[\mathrm{I}, \mathrm{II} / \mathrm{III}, \mathrm{IV}, \mathrm{V}]
\end{aligned}
$$

Note that though a constant source of site-specific precursor cells (constant $n_{i}$ ) was used in the model, their effective number is not unlimited. In the WT model precursor cells stop differentiating after the clearance of Tag-expressing cells, and in the tumor models activation of new $\mathrm{T}_{\mathrm{CD} 8} \mathrm{~s}$ is inhibited by large tumors (so that $\approx 15 \mathrm{~T}_{\mathrm{CD} 8} \mathrm{~s}$ are activated for 1000 tumor cells) and has a minimal effect after the first few days.

\section{SIMULATED IMMUNIZATIONS}

Immunization of transgenic mice was modeled, similarly to Kirschner and Panetta (1998), by introducing a variable $s_{i}$ that follows the clearance dynamics of Tag-transformed cells injected in WT mice by obeying the relation $d s_{i} / d t=-\gamma S_{i}$. In the presence of immunization, the $T$ equation becomes

$$
\begin{aligned}
\frac{d T_{i}}{d t}= & {\left[\left(c+s_{i}\right) \frac{M}{M+\sigma}\right]\left[n_{i}\left(1-\frac{M}{M+\alpha_{i}}\right)+T_{i}\right] } \\
& -w_{i} T_{i}, \quad i \in[\mathrm{I}, \mathrm{II} / \mathrm{III}, \mathrm{IV}, \mathrm{V}]
\end{aligned}
$$

\section{NULLCLINE ANALYSIS}

The nullcline analysis (Figures A2B-E in Appendix) is performed to study the effect of parameter values on the temporal trajectories of the tumor cells and site-specific $\mathrm{T}_{\mathrm{CD} 8 \mathrm{~s}}$ (Figures 2B-E). The nullcline analysis finds the equilibrium of the system when $M$ and $T_{i}$ are in a steady state $(d M / d t=d T / d t=0)$. Considering a single type of site-specific $\mathrm{T}_{\mathrm{CD} 8}$ for simplicity the equations become:

$$
\begin{aligned}
& \frac{d M}{d t}=0=r M-\frac{M}{M+\beta} b T \\
& \frac{d T}{d t}=0=c \frac{M}{M+\sigma}\left(n-n \frac{M}{M+\alpha}+T\right)-w T
\end{aligned}
$$

Solving these equations in terms of $M$ and $T$ yields

$$
\begin{aligned}
M & =\frac{b}{r} T-\beta \\
T & =\frac{c n \alpha M}{(M+\alpha)(M(w-c)+\sigma w)}
\end{aligned}
$$

For the biologically accepted range of $\beta(>0)$ in our model, $M=T=0$ is an unstable steady state. That is, for small number of tumor cells $(M)$ and $\mathrm{T}_{\mathrm{CD} 8} \mathrm{~s}(T)$, the value of tumor cells
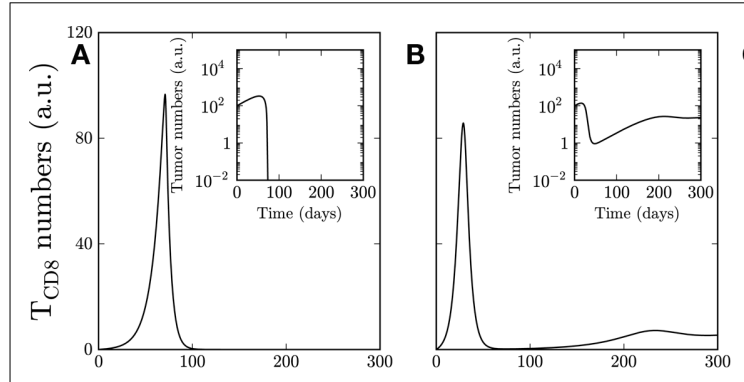

FIGURE 2 |The response of site IV-specific $T_{C D 8} s$ is shown in case of (A) clearance, (B) non-zero steady state, (C) oscillations, (D) tumor, and (E) uncontrolled response of Tag-expressing cells (Tag-expressing cells shown in insets). In all cases the initial condition is Tag-expressing cells $=100$, site IV-specific $T_{C D B}=0$. The
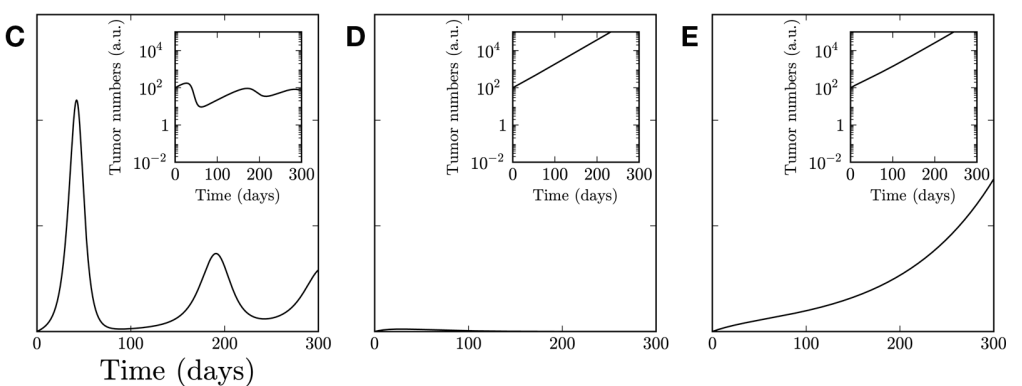

parameters $r=0.03 /$ day, $n=1.8$ (proportion), $b=0.5 /$ day, $c=0.5 /$ day, $w=0.2 /$ day, $\alpha=40$ cells, $\beta=\sigma=10$ cells are used in all figures with the following exceptions: (A) $n=0.3$ (proportion), $c=0.29 /$ day; (B) $\beta=\sigma=50 /$ day; (C) $\beta=\sigma=100 /$ day; (D) $c=0.15 /$ day;

(E) $c=0.21 /$ day. 
will always increase in the tumor model. Additional biologically significant steady states are discussed in Section "Results."

\section{SUMMARY OF PUBLISHED EXPERIMENTAL DATA}

We used published experimental data corresponding to $\mathrm{T}_{\mathrm{CD} 8} \mathrm{~s}$ derived from the spleen of WT C57BL/6 mice and three Tagtransgenic mouse strains that develop distinct tumors. Data corresponding to splenic $\mathrm{T}_{\mathrm{CD} 8}$ responses were used since they are available for all models and are representative for the systemic response to the antigen. In the case of brain tumors, $\mathrm{T}$ cell accumulation at the tumor site is correlated with spleen dynamics with a time lag (Ryan and Schell, 2006).

Tag-specific $\mathrm{T}_{\mathrm{CD} 8}$ cells are measured by $\mathrm{MHC}$ tetramer staining after encountering antigen which correlates with the number of $\mathrm{T}_{\mathrm{CD} 8} \mathrm{~s}$ that produce IFN $\gamma$ upon peptide-specific in vitro stimulation (Mylin et al., 2000). The published data and our own were obtained from two independent sets of experiments that were quantitatively different. In vivo model systems are often difficult to standardize. Hence, to account for lab-specific differences and to align the data, we scaled the data from Mylin et al. (2000) by a multiplicative factor that maximized the agreement.

The number of endogenous $\mathrm{T}_{\mathrm{CD} 8} \mathrm{~s}$ in Tag-transgenic mice can be very low and difficult to detect. Hence induction of detectable $\mathrm{T}_{\mathrm{CD} 8}$ responses can be stimulated by immunization of mice with Tag-transformed cells expressing full-length WT Tag or Tag variants in which specific determinants have been eliminated by mutagenesis. If immunization is not sufficient to induce the $\mathrm{T}$ cell response, due to deletion of $\mathrm{T}$ cell precursors during $\mathrm{T}$ cell development, then splenocytes from WT mice, which contain naïve $\mathrm{T}_{\mathrm{CD} 8} \mathrm{~s}$ as well as other immune cell subsets, are injected (adoptively transferred) into the Tag-transgenic mice. In such experiments, saturating amounts of splenocytes were given to achieve maximal $\mathrm{T}$ cell response.

\section{CHEMICALS AND REAGENTS}

All chemical reagents were purchased from Sigma-Aldrich (St Louis, MO, USA). RPMI-1640 with Glutamax and fetal bovine serum (FBS) were purchased from Invitrogen (Carlsbad, CA, USA). Benzonase ${ }^{\circledR}$ Nuclease was purchased from EMD Chemicals (San Diego, CA, USA). Annexin V Apoptosis Detection Kit, rat anti-mouse CD16/CD32 Fc block, Cytofix/Cytoperm, PermWash, fluorescein isothiocyanate (FITC), phycoerythrin (PE), allophycocyanin (APC) or APC-Cy7-labeled anti-mouse CD8 $\alpha$, PE-labeled anti-CD90.1, and FITC-labeled anti-5-bromo-2-deoxyuridine (BrdU) antibody were purchased from BD Biosciences (San Jose, CA, USA).

\section{ANIMALS}

Male and female C57BL/6 $\left(H-2^{b}\right)$ mice (4-6 weeks old) were purchased from The Jackson Laboratory (Bar Harbor, Maine) and routinely used between the ages of 7 and 12 weeks. SV11 $\left(\mathrm{H}-2^{\mathrm{b}}\right)$ mice express full-length SV40 T Ag under the control of the SV40 promoter (Brinster et al., 1984). Line SV11 mice were maintained by breeding hemizygous Tag transgene+ males with C57BL/6J females and transgene positive animals identified as previously described (Schell et al., 1999). TCR-IV transgenic mice expressing the TCR $\alpha$ and TCR $\beta$ chains specific for Tag site IV have been previously described (Tatum et al., 2008) and were maintained by breeding transgene positive males with B6.PL-Thy $1^{a} / \mathrm{CyJ}$ females. All mice were maintained in the animal facility at the Pennsylvania State University College of Medicine, Hershey, PA, USA and experiments were performed under guidelines approved by the Institutional Animal Care and Use Committee.

\section{IMMUNIZATION AND IDENTIFICATION OF SITE-SPECIFIC $T_{\text {CD8 }} \mathbf{s}$}

The B6/WT-19 cell line was derived previously by transformation of B6 mouse embryo fibroblasts with WT SV40 strain VA45-54 (Pretell et al., 1979; Tevethia et al., 1980). Production and characterization of the $\mathrm{D}^{\mathrm{b}} /$ Tag site $\mathrm{I}(\mathrm{Db} / \mathrm{I}), \mathrm{K}^{\mathrm{b}} / \mathrm{Tag}$ site IV $(\mathrm{Kb} / \mathrm{IV})$, $\mathrm{D}^{\mathrm{b}}$ /influenza virus (Flu) nucleoprotein (NP) 366-374 (Db/Flu), and $\mathrm{K}^{\mathrm{b}} / \mathrm{HSV}$ gB 498-505 (Kb/gB) PE-conjugated tetramers were described previously (Mylin et al., 2000). For immunization, $5 \times 10^{7}$ live B6/WT-19 cells were injected by the intraperitoneal route. For adoptive transfer, SV11 or transgene negative mice were injected intravenously with lymphocytes derived from TCRIV transgenic mice containing $5 \times 10^{5}$ clonotypic site IV-specific $\mathrm{T}_{\mathrm{CD} 8} \mathrm{~s}$. For tetramer staining, mouse spleens were harvested at the indicated time points post immunization and processed to single cell suspensions as previously described (Schell et al., 1999). Erythrocyte-depleted splenocytes were washed twice in PBSFBS [PBS supplemented with $2 \%$ (vol/vol) FBS], resuspended at $2 \times 10^{7}$ cells $/ \mathrm{ml}$ in PBS-FBS, and incubated with rat anti-mouse CD16/CD32 $(33 \mathrm{mg} / \mathrm{ml})$ for $15 \mathrm{~min}$ on ice. Following incubation, cells were washed once in PBS-FBS and resuspended in fluorescence-activated cell sorter (FACS) buffer [PBS-FBS supplemented with $0.1 \%$ (wt/vol) sodium azide]. Aliquots containing $2 \times 10^{6}$ cells were prepared and the appropriate MHC tetramer plus anti-mouse CD $8 \alpha$ antibody were added. Alternatively, TCRIV transgenic $\mathrm{T}$ cells were identified according to their surface expression of CD90.1. In this case, cells were incubated with anti-CD90.1 antibody at room temperature for $15 \mathrm{~min}$ as well as anti-CD8 and MHC tetramer to minimize non-specific staining. Proliferation and apoptosis analysis focused on the population of CD8+, Tetramer+, and CD90.1+ cells. Cells were then resuspended in FACS buffer and kept on ice or processed into apoptosis assay prior to flow cytometry.

\section{APOPTOSIS ASSAY}

$2 \times 10^{6}$ erythrocyte-depleted and MHC tetramer- and/or antiCD90.1-stained cells were incubated with conjugated Annexin $\mathrm{V}$ and 7-AAD (1:100 dilution) in $100 \mu \mathrm{l} 1 \times$ Annexin V staining buffer for $15 \mathrm{~min}$ at room temperature in the dark. Cells were immediately assessed by flow cytometry (BD FACSCalibur or FACSCanto). At least 10000 events were collected in the live cell gate and analyzed for Annexin V and 7-AAD staining. Annexin V negative, 7-AAD positive cells were considered non-viable and excluded from further analysis.

\section{IN VIVO 5-BROMO-2-DEOXYURIDINE INCORPORATION ASSAY}

Mice received a $1-\mathrm{mg}$ dose of $1 \mathrm{mg} / \mathrm{ml}$ BrdU solution (diluted in PBS) $3 \mathrm{~h}$ before sacrifice by intraperitoneal injection at the indicated times post immunization. Splenocytes were stained for BrdU incorporation using a modified staining protocol (BD Biosciences). Briefly, $2 \times 10^{6}$ splenocytes were stained with $\mathrm{MHC}$ 
tetramers and anti-mouse $\operatorname{CD} 8 \alpha$ as described above. Cells were then resuspended in $100 \mu \mathrm{l}$ of Cytofix/Cytoperm (Becton Dickinson) and incubated for $30 \mathrm{~min}$ at room temperature. The cells were washed once with $1 \times$ PermWash, resuspended again in $100 \mu \mathrm{l}$ of Cytofix/Cytoperm and incubated for $10 \mathrm{~min}$ at room temperature. Cells were washed again and resuspended in $100 \mu \mathrm{l}$ Cytofix/Cytoperm and incubated for $5 \mathrm{~min}$ at room temperature. After one wash, cells were incubated at $37^{\circ} \mathrm{C}$ for $1 \mathrm{~h}$ with $20 \mathrm{U}$ Benzonase nuclease in $100 \mu$ l DPBS with $1 \mathrm{mM} \mathrm{MgCl} 2$ and washed once. Cells were then stained with $5 \mu \mathrm{l}$ of FITC-labeled antiBrdU antibody (eBioscience) in $40 \mu \mathrm{l} 1 \times$ PermWash for $20 \mathrm{~min}$ at room temperature. Cells were washed and then fixed with 2\% paraformaldehyde in PBS and analyzed by flow cytometry as above.

\section{STATISTICAL TESTS}

We performed the Welch two-sample $t$-test to assess whether the ratio of the percentage of site $\mathrm{IV}$-specific $\mathrm{T}_{\mathrm{CD} 8} \mathrm{~s}$ proliferating in WT to the similar percentage in SV11 mice is significantly greater than the similar ratio of the apoptotic cells. Three data points were taken from the WT mice and four data points were taken from SV11 mice. To construct the two groups for the statistical test we used the percentage of proliferating and apoptotic cells in all combinations in which WT values were in the numerator.

\section{RESULTS \\ OVERVIEW OF TUMOR GROWTH (M) AND T CD8 $_{\text {DYNAMICS }}$}

To study the characteristics of $\mathrm{T}_{\mathrm{CD} 8} \mathrm{~s}$ modulation during tumor development we developed a dynamic model of the interactions between tumor cells $(M)$ and $\mathrm{T}_{\mathrm{CD} 8}\left(T_{i}\right)$ cells elicited in response to the four unique determinants of Tag. In this section we discuss the repertoire of dynamical behaviors that emerged from the model by describing the site IV-specific $\mathrm{T}_{\mathrm{CD} 8} \mathrm{~s}$ in response to the growing tumor (refer to Materials and Methods and Appendix for details). Tag-expressing cells exponentially proliferate at rate $r$ and are killed by $\mathrm{T}_{\mathrm{CD} 8} \mathrm{~s}$ at a rate that grows with tumor size, until the tumor size becomes large compared to $\beta$ (Figure A1 in Appendix); after which the killing rate saturates to a rate $b$. Site IV-specific $\mathrm{T}_{\mathrm{CD} 8} \mathrm{~s}$ are activated against the tumor cells and proliferate but their differentiation is subsequently suppressed by the increasing tumor size and they also undergo natural death at rate $w_{\mathrm{iv}}$. Proliferation and activation of $\mathrm{T}_{\mathrm{CD} 8} \mathrm{~s}$ is suppressed by large tumors and the suppression is modeled by Michaelis-Menten functions parameterized by $\sigma$ and $\alpha_{i}$ respectively.

A repertoire of dynamical behaviors emerged from the model including clearance of Tag-expressing cells, as in WT mice, or tumor formation, as in Tag-transgenic mice. If Tag-expressing cells are cleared, the $\mathrm{T}$ cell response contracts (Figure 2A). Tagexpressing cells and T cells can also reach homeostasis (Figure 2B), as is observed when mice are immunized prior to the development of Tag-induced pancreatic tumors (Otahal et al., 2006). In some cases, the number of $\mathrm{T}_{\mathrm{CD} 8}$ and Tag-expressing cells fluctuate for extended periods of time before reaching a steady state (Figure 2C). If the $\mathrm{T}_{\mathrm{CD} 8}$ response is incapable of controlling the proliferating Tag-expressing cells, they increase exponentially, and $\mathrm{T}_{\mathrm{CD} 8} \mathrm{~s}$ either undergo tolerance, becoming unresponsive (Figure 2D), or themselves expand continuously (Figure 2E).
To understand the effect of the parameter values on the dynamic behavior we performed a nullcline analysis (refer to Materials and Methods and Appendix for details). The nullcline analysis provides the long-term outcome resulting from the trajectories of change in the concentrations of Tag-expressing cells and $\mathrm{T}_{\mathrm{CD} 8} \mathrm{~s}$. The clearance scenario (Figure 2A; Figure A2A in Appendix) shows increasing initial trajectories of Tag-expressing cells and $\mathrm{T}_{\mathrm{CD} 8} \mathrm{~s}$. The increasing efficiency of $\mathrm{T}_{\mathrm{CD} 8}$-mediated killing of tumor cells leads to first a slowing down of the increase, and later a decrease in tumor cell numbers (modeled by the value of $M$ ). When the number of Tag-expressing cells is below a certain threshold value given by the nullcline analysis, $\mathrm{T}_{\mathrm{CD} 8} \mathrm{~s}$ begin decreasing and eventually Tag-expressing cells and $\mathrm{T}_{\mathrm{CD} 8} \mathrm{~s}$ are depleted. In the clearance scenario the $\mathrm{T}_{\mathrm{CD} 8}$ response is maximized by setting the MichaelisMenten constant $\alpha_{i}$, which models the effect of tumor size on the recruitment of new $\mathrm{T}_{\mathrm{CD} 8} \mathrm{~s}$, higher than the Tag-expressing cells. Though lower values of $\alpha_{i}$ are used in the tumor models, increasing $\alpha_{i}$ cannot clear the tumor cells because it stimulates the differentiation of effector cells from naïve $T$ cells which is a linear process and has a limited role in the control of exponential tumor growth (Figure A1 in Appendix).

The nullcline analysis identified the salient parameters that drive the system from one behavior type to another (Figures 2B-E). Unlike in the clearance scenario in which tumor cells are cleared, a larger value of Michaelis-Menten constants $\beta$ and/or $\sigma$, which model the effect of tumor size on the $\mathrm{T}_{\mathrm{CD} 8}$ activity, launch a protective $\mathrm{T}_{\mathrm{CD} 8}$ response characterized by a steady state like behavior (Figure 2B; Figure A2B in Appendix). Further increase in these Michaelis-Menten constants ( $\beta$ and/or $\sigma$ ) leads to extended oscillations of $\mathrm{T}_{\mathrm{CD} 8} \mathrm{~s}$ and tumor cells (Figures $2 \mathrm{C}$ and 3; Figure A2C in Appendix). As expected, decreased tumor growth (lower $r$ ) and increased $\mathrm{T}_{\mathrm{CD} 8}$-mediated killing $(b)$ (Figure 2E; Figure A2E in Appendix) pushes the system toward tumor clearance. The extreme cases when $r<0$ are not relevant in the systems that lead to tumor formation. In the following sections we consider the dynamics of all the determinants in which case site-specific $\mathrm{T}_{\mathrm{CD} 8}$ apoptosis rates and inhibition by tumor cells lead to the characteristic $\mathrm{T}_{\mathrm{CD} 8}$ response against each determinant.

Though various parameters can affect the fate of the tumors and consequently the $\mathrm{T}_{\mathrm{CD} 8}$ response, only the net growth of $\mathrm{T}_{\mathrm{CD} 8} \mathrm{~S}$, described by the difference between the rate of activation (c) and cell death $\left(w_{i}\right)$, decides the tolerance behavior (unresponsiveness of the $\mathrm{T}_{\mathrm{CD} 8}$ cells). Decrease in the net growth transitions the system from a clearance state (if $c-w_{i}$ is positive and large) observed in WT mice to a tumor state observed in transgenic mice (if $c-w_{i}$ is negative; see Figure 2D; Figure A2D in Appendix). Thus to reproduce the tolerance of $\mathrm{T}_{\mathrm{CD} 8} \mathrm{~s}$ observed in Tag-transgenic mice $w_{i}$ is assumed to be greater than $c$ in all tumor models. Our parameter analysis (Figure A3 in Appendix) indicates a large deviation from the experimental results when the above condition on the net growth of $\mathrm{T}_{\mathrm{CD} 8} \mathrm{~s}$ is not implemented.

\section{TCD8 NET GROWTH AND TOLERANCE}

The $\mathrm{T}_{\mathrm{CD} 8}$ response to Tag in WT mice and in transgenic mice bearing tumors provides two unique immunological environments which are modeled by assuming positive and negative net growth $\left(c-w_{i}\right)$ of $\mathrm{T}_{\mathrm{CD} 8} \mathrm{~s}$ in $\mathrm{WT}$ and transgenic mice respectively. The fact 
that the $\mathrm{T}_{\mathrm{CD} 8}$ response is strong in WT mice but is undetectable in transgenic mice (Schell et al., 2000; Otahal et al., 2006) lends support to this assumption. The early expression of antigen in Tag-transgenic mice might lead to a lower rate of expansion (c) of $\mathrm{T}_{\mathrm{CD} 8} \mathrm{~s}$, allowing tumors to grow. Indeed, it is experimentally observed that high amounts of antigen reduce the proliferation of $\mathrm{T}_{\mathrm{CD} 8} \mathrm{~s}$ during tolerance (Ganss and Hanahan, 1998).

To validate our hypothesis of the positive versus negative net growth of $\mathrm{T}_{\mathrm{CD} 8} \mathrm{~S}$ in WT versus transgenic mice we experimentally assessed proliferation and apoptosis of $\mathrm{T}_{\mathrm{CD} 8} \mathrm{~s}$ in both WT mice and Tag-transgenic mice bearing brain tumors (Schell et al., 1999). It is difficult to obtain the absolute value of the rate of activation $(c)$ and the rate of apoptosis $\left(w_{i}\right)$ through experimentation, which renders it improper to directly compare the experimental values. However, we noticed that if the net growth is positive in WT $\left(w_{\mathrm{WT}}<c_{\mathrm{WT}}\right)$ and negative in transgenic mice $\left(w_{\text {Tumor }}>c_{\text {Tumor }}\right)$, it implies that for a specific $\mathrm{T}_{\mathrm{CD} 8}$ clone, the ratio of proliferation rates in WT to transgenic mice is greater than the similar ratio of apoptosis rates $\left[\left(c_{\mathrm{WT}} / c_{\text {Tumor }}\right)>\left(w_{\mathrm{WT}} / w_{\text {Tumor }}\right)\right]$. The converse implication is satisfied if the rates of $\mathrm{T}$ cell proliferation are comparable in WT and tumor-bearing mice. To test this relationship, we utilized $\mathrm{T}_{\mathrm{CD} 8}$ s from TCR transgenic mouse line TCR-IV in which $90 \%$ of the $\mathrm{T}_{\mathrm{CD} 8} \mathrm{~s}$ were specific for site IV (Tatum et al., 2008). Splenocytes isolated from TCR-IV transgenic mice were adoptively transferred into groups of 3 4 WT or SV11 mice before immunization with Tag-expressing cells. The percentage of proliferating and apoptotic TCR-IV cells recovered from the recipients was assessed through in vivo BrdU incorporation assay (Figure 3B) and Annexin V apoptosis assay (Figure 3C) on days 3 and 4 after immunization, respectively. These data were subsequently used to estimate the ratio of proliferation ( $\mathrm{P}$ ratio $\left.-c_{\mathrm{WT}} / c_{\text {Tumor }}\right)$ and apoptosis (A ratio $-w_{\mathrm{WT}} / w_{\text {Tumor }}$ ) rates of site IV-specific $\mathrm{T}_{\mathrm{CD} 8} \mathrm{~s}$ in WT to transgenic mice. As shown in Figure 3D, the value of the proliferation ratio is higher than the apoptosis ratio for both time points, and the difference is statistically significant $[P<0.032$ $(t=2.07)$ at 3 days and $P<0.0001(t=4.57)$ at day 4 after immunization]. Moreover, different trends of change in the frequency of TCR-IV cells in WT and brain tumor-bearing transgenic mice
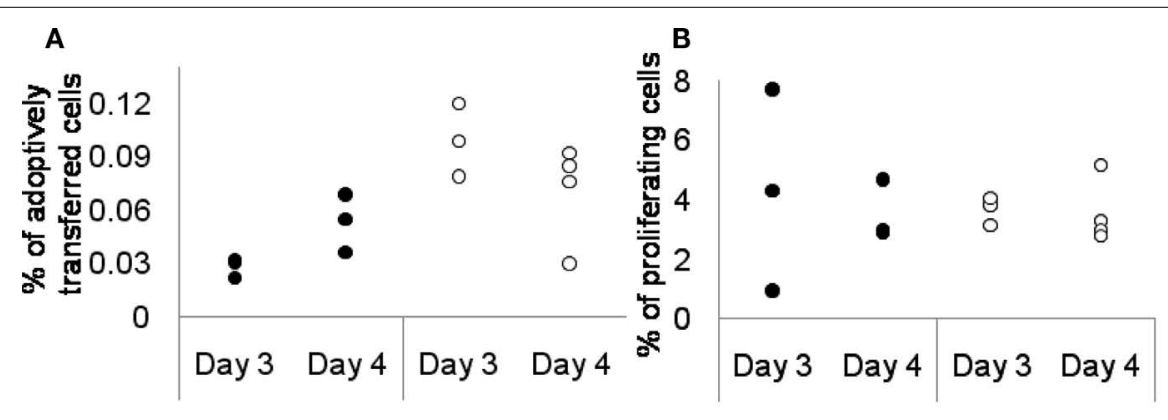

C

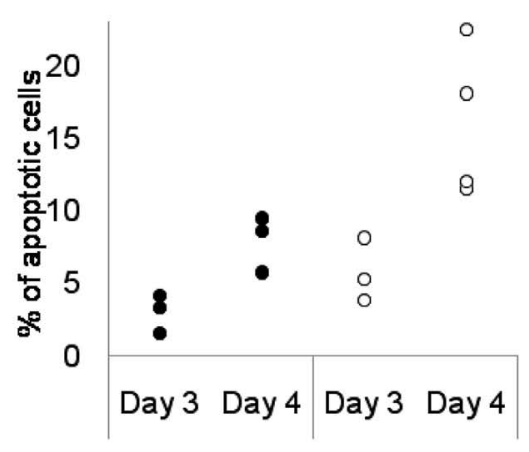

FIGURE 3 | Site IV-specific $\mathrm{T}_{\mathrm{CD} 8} \mathrm{~s}$ have different proliferation and apoptosis kinetics under WT and tumor conditions. Data was obtained 3 and 4 days after immunization using Tag-expressing cells. From (A) to (C), each circle represents data obtained from one mouse, either WT (•) or SV11 (o). (A) The percentage of adoptively transferred site IV-specific $T_{\mathrm{CD} 8} \mathrm{~S}$ in total splenocytes as assessed by flow cytometry. Although not statistically significant, there was an increase of site IV-specific $T_{C D 8}$ s percentage in WT mice, but a decrease of site IV-specific $T_{C D 8}$ s percentage in SV11. Site IV-specific $T_{\mathrm{CD} 8} \mathrm{~S}$ was defined as CD8+, Tetramer IV+ (indicating $T$ cells specific for epitope IV), and CD90.1+ (indicating T cells derived from the TCR-IV mouse line). (B) The percentage of proliferating site IV-specific $T_{C D 8} S$ in total CD8+ T cells of WT and SV11 mice after immunization as assessed by

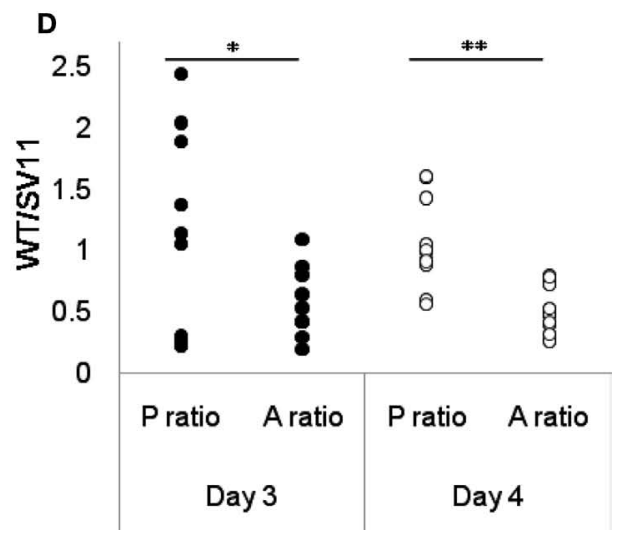

BrdU assay. The proliferation rate remained similar under WT and SV11 condition. (C) The percentage of apoptotic site IV-specific $T_{\mathrm{CD} 8} \mathrm{~S}$ in total CD8+ cells of WT and SV11 mice as assessed by apoptosis assay. Although not statistically significant, there is an increase of apoptotic site IV-specific $T_{C D 8} S$ percentage in both WT and SV11, with SV11 more so than WT. (D) The WT to SV11 ratio of percentages of proliferating site IV-specific $T_{C D 8} S$ ( $P$ ratio: proliferation ratio) and the same ratio of percentages of apoptotic site IV-specific $T_{C D 8} S$ (A ratio: apoptosis ratio) for both time points. Each circle indicates one possible ratio between WT data and SV11 data at the same time point, either proliferation ratio (•) or apoptosis ratio (०). Proliferation ratio is higher than the apoptosis ratio at day $3\left({ }^{*} P<0.032, t=2.07\right)$ and day 4 ( $\left.{ }^{*} P<0.0001, t=4.57\right)$. 
between days 3 and 4, with a slight increase in TCR-IV T cells in WT and slight decrease in TCR-IV $\mathrm{T}$ cells in transgenic mice (Figure 3A) suggest that the rate of apoptosis is higher than the rate of proliferation in the presence of tumors. The results suggest that the net growth in $\mathrm{T}_{\mathrm{CD} 8} \mathrm{~s}$ is negative in transgenic mice, while positive in WT mice, assuming that the proliferation rate of the $\mathrm{T}_{\mathrm{CD} 8}$ clones in WT and transgenic mice is in a comparable range. Next, we discuss the dynamics of site-specific $\mathrm{T}_{\mathrm{CD} 8} \mathrm{~s}$ in $\mathrm{WT}$ and transgenic mice.

\section{RESPONSE OF WT MICE TO IMMUNIZATION WITH TAG-TRANSFORMED CELLS}

We used our own experimental data (closed symbols in Figure 4) and the data from (Mylin et al., 2000; open symbols in Figure 4) to model the behavior of the $\mathrm{T}_{\mathrm{CD}}$ response to the four $\mathrm{H}-2^{\mathrm{b}}$ restricted Tag determinants following immunization with Tagtransformed cells in WT mice. Mice were immunized with $5 \times 10^{7}$ SV40 Tag-transformed cells and the site-specific $\mathrm{T}_{\mathrm{CD} 8}$ response was analyzed by staining with site-specific MHC tetramers at the indicated time points. The simulations of the $\mathrm{T}_{\mathrm{CD} 8}$ activity were then fit to the experimental data (Figure 4).

Figure 4 shows that $\mathrm{T}_{\mathrm{CD} 8} \mathrm{~s}$ specific for site IV are highest in numbers followed by $\mathrm{T}_{\mathrm{CD} 8} \mathrm{~s}$ specific for site $\mathrm{I}$ and then $\mathrm{T}_{\mathrm{CD} 8} \mathrm{~s}$ specific for site II/III. The model can reproduce the observation that the addition of excess site I-specific precursor cells reverses the hierarchy so that the number of $\mathrm{T}_{\mathrm{CD} 8} \mathrm{~s}$ specific to site $\mathrm{I}$ is higher than that of site IV-specific $\mathrm{T}_{\mathrm{CD} 8}$ s (Tatum et al., 2010). This

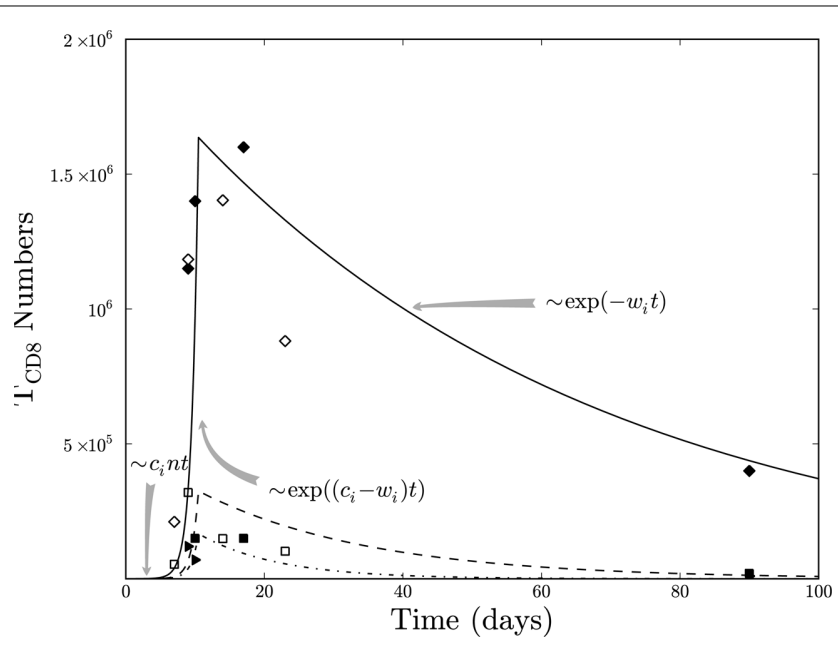

FIGURE 4 | Simulated (lines) and experimental (symbols) $T_{\mathrm{CD} 8} \mathbf{s}$ in response to the immunization of WT mice with Tag-transformed cells. The response of site I-, II/III-, IV-, and V-specific $T_{\mathrm{CD} 8} \mathrm{~S}$ is shown by the solid, dashed, dash-dot, and dotted lines, respectively. The gray arrows represent the terms in the mathematical model dominating the dynamics. The data from Mylin et al. (2000); empty symbols) and current study (filled symbols) representing site I (squares), II/III (triangles), and IV (diamonds) specific

$T_{C D 8} S$ is shown. The data from Mylin et al. (2000) is scaled by a multiplicative factor to minimize the variation between the two experiments. The initial conditions were, $T_{C D 8} s=0$, and Tag-expressing cells (non-proliferating) $=10^{6}$. The parameter values are $n=5 \times 0.3 / 1 / 4$ proportion for site $\mathrm{V} / \mathrm{I} / \mathrm{IV}$ respectively, $b=0.50 /$ day, $c=1.08 /$ day, $w_{1}=0.04 /$ day, $w_{\|/\|}=0.09 /$ day, $w_{\mathrm{IV}}=0.02 /$ day, $w_{\mathrm{v}}=1.02 /$ day, $\alpha_{i}=1 \mathrm{E} 100$ cells . result indicates that the dominance hierarchy, at least among the three most dominant determinants, is impacted by the precursor frequency. However, the undetectable numbers of site V-specific $\mathrm{T}_{\mathrm{CD} 8} \mathrm{~s}$ are not explained by a lower precursor frequency but due to their smallest net growth upon exposure to the antigen. These cells become detectable upon immunization with mutated Tag expressing only site $\mathrm{V}$ determinant because of the availability of tumor cells to drive their proliferation. For the fit shown in Figure 4 at the peak of the response, the hierarchy of the Tag site-specific $\mathrm{T}_{\mathrm{CD}} 8$ response is dependent on the site-specific activation of new $\mathrm{T}_{\mathrm{CD} 8} \mathrm{~s}$ and the apoptosis rates. The proliferation rate $(c)$ is kept the same for all site-specific $\mathrm{T}_{\mathrm{CD} 8} \mathrm{~s}$ since it was not required to be different to reproduce the observed data in Figure 4.

The $\mathrm{T}_{\mathrm{CD} 8}$ dynamics can be characterized by an initial linear conversion of naïve cells into activated $\mathrm{T}_{\mathrm{CD} 8} \mathrm{~s}$ in response to tumor cells, followed by exponential growth of the $\mathrm{T}_{\mathrm{CD} 8} \mathrm{~s}$. As a result, the number of tumor cells rapidly decreases toward 0 (not shown). In simulations, tumor cells are cleared around day 10, which coincides with the experimentally observed time after which minimal effector $\mathrm{T}_{\mathrm{CD} 8}$ are proliferating. When tumor cell numbers become negligible, the contraction phase of $\mathrm{T}_{\mathrm{CD} 8} \mathrm{~s}$ begin which is dominated by exponential decay (at the rate $w_{i}$ ). In this phase, the relationships between the rates of apoptosis $\left(w_{i}\right)$ of site-specific $\mathrm{T}_{\mathrm{CD} 8} \mathrm{~s}$ can be estimated.

$\mathrm{T}_{\mathrm{CD} 8} \mathrm{~s}$ targeting the dominant site IV and subdominant site I make up $80 \%$ of the Tag-specific $\mathrm{T}_{\mathrm{CD} 8}$ response. The model predicts that the only way to reproduce the highest and most prolonged site IV-specific $\mathrm{T}_{\mathrm{CD}}$ response is to have a lower apoptosis rate for site IV-specific $\mathrm{T}_{\mathrm{CD} 8} \mathrm{~s}$ compared to site I-specific $\mathrm{T}_{\mathrm{CD} 8} \mathrm{~s}$ $\left(w_{\text {IV }}<w_{\mathrm{I}}\right)$. To test this novel prediction of site-specific apoptosis rates, we immunized groups of three WT mice by intraperitoneal injection of C57BL/6-derived Tag-transformed cells. The percentage of apoptotic and proliferating $\mathrm{T}_{\mathrm{CD} 8} \mathrm{~s}$ specific for site I and IV was assessed 9 and 14 days after immunization as estimations of the respective rates of apoptosis and proliferation. In addition, the percentage of site I-specific and site IV-specific $\mathrm{T}_{\mathrm{CD} 8} \mathrm{~s}$ in splenocytes was assessed 7, 9, 14, and 23 days after immunization. Since the model estimates the relationship between the two rates of apoptosis when the activation of the $\mathrm{T}_{\mathrm{CD} 8} \mathrm{~s}$ is minimal, we tested our prediction after day 14 when no significant proliferation was observed in the experiments (Figure 5A). As shown in Figure 5B, the percentage of apoptosis for site I-specific $T_{C D 8}$ was significantly higher than for site IV-specific $\mathrm{T}_{\mathrm{CD} 8} \mathrm{~s}(P<0.012)$. A differential cell death rate was also reflected in Figure 5C, which showed the percentage of site-specific $\mathrm{T}_{\mathrm{CD} 8} \mathrm{~s}$ in splenocytes. While the percentage of site IV-specific $\mathrm{T}_{\mathrm{CD} 8} \mathrm{~s}$ remained consistent after day 9 , there was a drop in the percentage of site I-specific $\mathrm{T}_{\mathrm{CD} 8} \mathrm{~S}$ between day 9 and day 14. Taken together, these results suggest that site I-specific $\mathrm{T}_{\mathrm{CD} 8} \mathrm{~s}$ undergo cell death at a higher average rate compared to site $\mathrm{IV}$-specific $\mathrm{T}_{\mathrm{CD} 8} \mathrm{~s}$, explaining the prolonged high level accumulation of site IV-specific T cells. We note that the same rates of proliferation for site I- and IV-specific $\mathrm{T}_{\mathrm{CD} 8} \mathrm{~s}$ are used in the model; a parsimonious assumption which is also supported by Figure 5A. However, day 9 is at the end of the expansion phase and many parameters in addition to the proliferation rates may play a role in explaining the observations (Figures 5A,B). 


\section{CD8+ T CELL RESPONSE IN TRANSGENIC MICE}

The three Tag-transgenic systems that autonomously develop tumors vary in the lifespan of the mice, metastasis of the tumors, responsiveness to immune-therapies and tolerance of $\mathrm{T}_{\mathrm{CD} 8} \mathrm{~s}$. The computer simulations were run to cover the duration of the life span for each transgenic mouse line. The simulated tumor phenotype reproduces the exponential tumor growth and $\mathrm{T}_{\mathrm{CD} 8}$ expansion during the early period of antigen expression, followed by an unresponsiveness of $\mathrm{T}_{\mathrm{CD} 8} \mathrm{~s}$. The tolerance onset time is different for site-specific $\mathrm{T}_{\mathrm{CD} 8} \mathrm{~s}$ in different transgenic mouse lines. This information was used to parameterize the apoptosis rates (Table 1; Figure A3A in Appendix) and all the other parameters were kept the same across different tumor models. Figures 6A,B reproduce the sequential loss (tolerance onset) of site-specific $\mathrm{T}_{\mathrm{CD} 8} \mathrm{~s}$ in pancreatic tumor (Otahal et al., 2006) and osteosarcoma (Schell et al., 2000) models, respectively. Tissue specific death rates for $T_{C D 8} s$ against each site $\left(w_{i}\right)$ reproduce the correct tolerance onset in different transgenic mouse lines. We observed interesting regularities between the rates of apoptosis. For example, the apoptosis rate of site I-specific $\mathrm{T}_{\mathrm{CD} 8} \mathrm{~s}$ is always greater than that of site
IV-specific $\mathrm{T}_{\mathrm{CD} 8} \mathrm{~s}$ as seen in the WT model. Thus while the specific values of the parameters can be different, the unavoidable similarities pointed out by our dynamic model can improve our understanding of the tumor growth and $\mathrm{T}_{\mathrm{CD} 8}$ response.

Changes in the other parameters including the growth rate of tumor cells $(r)$ and the rate of $\mathrm{T}_{\mathrm{CD} 8}$ mediated killing of tumor cells $(b)$ were not necessary to reproduce any of the observations, though they could affect the modeled tumor size. The unresponsiveness of $\mathrm{T}_{\mathrm{CD} 8} \mathrm{~s}$ targeting particular determinants was confirmed by the absence of $\mathrm{T}_{\mathrm{CD} 8}$ activation after simulating in silico immunization with Tag-expressing cells (modeled by $s_{i}$; Figure 7). In the brain tumor model (Schell et al., 1999) $\mathrm{T}_{\mathrm{CD} 8} \mathrm{~s}$ specific for the three most dominant Tag sites undergo central tolerance; hence we only see the $\mathrm{T}_{\mathrm{CD} 8} \mathrm{~s}$ specific for the immunorecessive site $\mathrm{V}$ which remain responsive throughout the lifespan of these transgenic mice. However, the simulations indicate that the activity of these $\mathrm{T}_{\mathrm{CD} 8} \mathrm{~s}$ is lower than in WT mice (Figure 6C).

Next, we used our model to predict the peak of $\mathrm{T}_{\mathrm{CD}}$ accumulation, since tumor treatment is most effective when active $\mathrm{T}_{\mathrm{CD} 8} \mathrm{~s}$ are high. The tumor as well as WT models predict that site $\mathrm{I}_{\mathrm{CD} 8} \mathrm{~s}$ peak
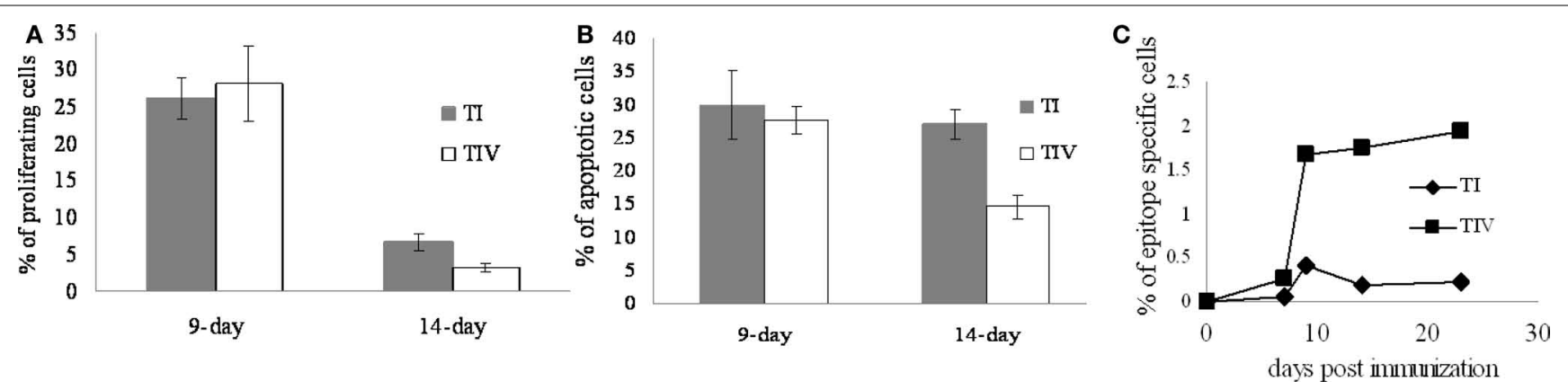

FIGURE 5 | Site I- and site IV-specific $\mathrm{T}_{\mathrm{CD} 8} \mathrm{~s}$ have different apoptosis kinetics after immunization. (A) Percentage of proliferating cells assessed by BrdU proliferation assay and (B) Annexin $V$ positive cells indicating apoptotic cells among site I (filled) and site IV (empty) specific $T_{C D 8} S$. The site I-specific $T_{C D 8} S$ undergoing apoptosis are significantly higher than site IV-specific $T_{\mathrm{CD} 8} \mathrm{~S}\left({ }^{*} P<0.012\right.$ ). (C) Percentage of site I-specific $T_{C D 8} S(\diamond)$ and site IV-specific $T_{C D 8} S(\square)$ among total splenocytes 7, 9, 14, and 23 days after immunization. Comparing to site IV-specific $T_{\mathrm{CD} 8} \mathrm{~S}$, there is a drop in the percentage of site I-specific $T_{C D 8} S$ between days 9 and 14 .

Table 1 | Model parameters and description.

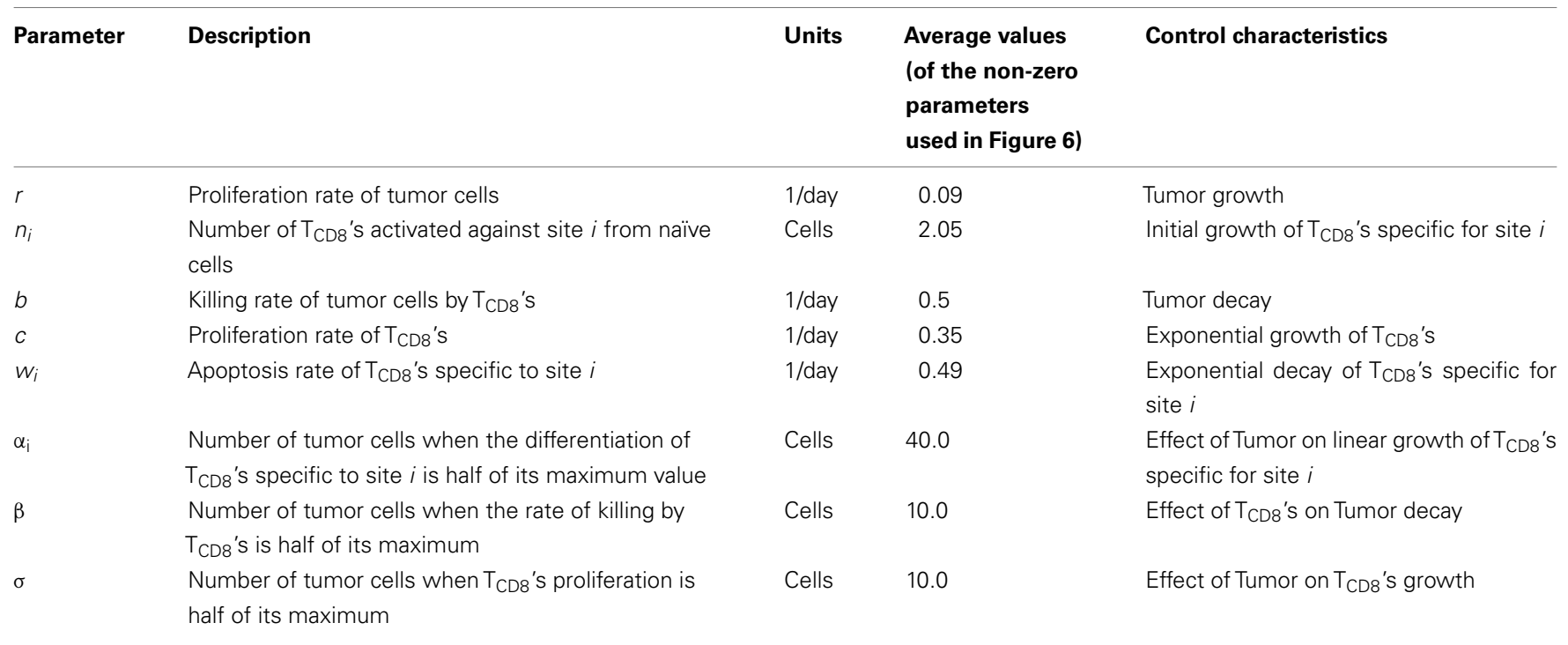




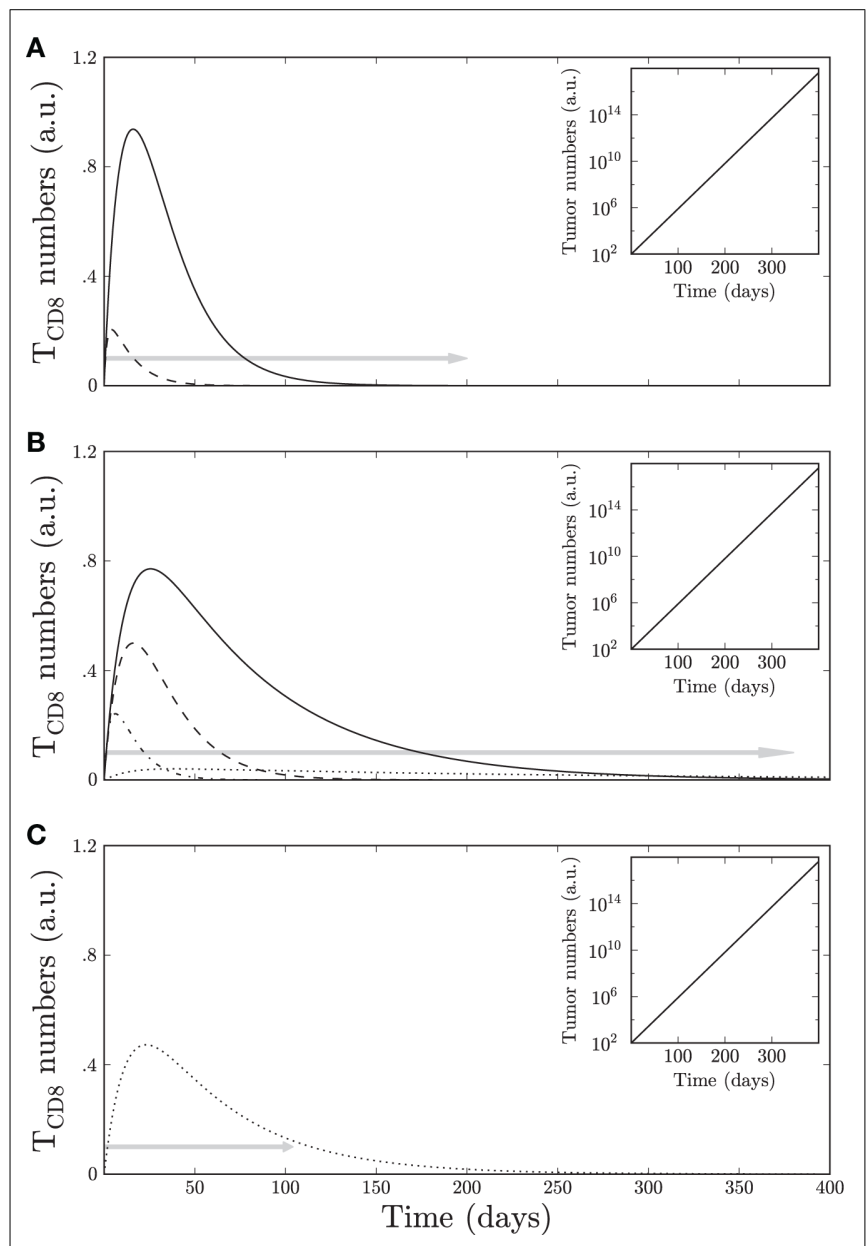

FIGURE 6 | Simulated $T_{\mathrm{CD} 8}$ s response in (A) pancreatic tumors, (B) osteosarcomas, and $(\mathbf{C})$ brain tumors. $Y$-axis depicts the number of $T_{\mathrm{CD} 8} \mathrm{~S}$ in arbitrary units and $x$-axis depicts the time in days. Site I-specific $T_{C D 8} S$ is shown with a dashed line, $T_{\text {I/III }}$ with a dash-dot line, site IV-specific $T_{C D 8} S$ with a solid line, and $T_{\vee}$ with a dot line. Light gray arrows show the average lifespan of mice. All cases show a sequential loss of $T_{C D 8}$ cells against different sites. The insets indicate tumor growth.

earlier than site IV $\mathrm{T}_{\mathrm{CD} 8} \mathrm{~s}$ (Mylin et al., 2000). In osteosarcomas, site I-specific $\mathrm{T}_{\mathrm{CD} 8} \mathrm{~s}$ reach higher numbers than in pancreatic tumors (Figure 6B). The peaks in $\mathrm{T}_{\mathrm{CD} 8}$ accumulation in the osteosarcoma model occur at later time points (at 18 days for $T_{\mathrm{CD} 8 \mathrm{I}}$ and 24 days for $\left.T_{\mathrm{CD} 8 \mathrm{IV}}\right)$ as compared to the peaks of site I-specific $\mathrm{T}_{\mathrm{CD} 8} \mathrm{~s}$ (4th day) and site IV-specific $\mathrm{T}_{\mathrm{CD} 8} \mathrm{~s}$ (7th day) in the pancreatic model (compare Figures 6A,B). The brain tumor model (Figure 6C) predicts an earlier peak of site $\mathrm{V}$-specific $\mathrm{T}_{\mathrm{CD} 8} \mathrm{~s}$ compared to the osteosarcoma model (days 23 and 30, respectively) since $\mathrm{T}_{\mathrm{CD} 8} \mathrm{~s}$ targeting the dominant sites are absent, resulting in increased availability of antigen. Thus our model can detect the differences in the timing of the peaks in different models.

In conclusion, the tumor models give insight into the tissue specificity, for example revealing that osteosarcomas elicit a stronger response as compared to pancreatic tumors. All tumors inhibit activation of naïve cells and reduce the net growth of $\mathrm{T}_{\mathrm{CD} 8}$ cells but differences in the apoptosis rates of the recruited $\mathrm{T}_{\mathrm{CD} 8} \mathrm{~s}$ is a critical factor in determining a tissue-specific response.

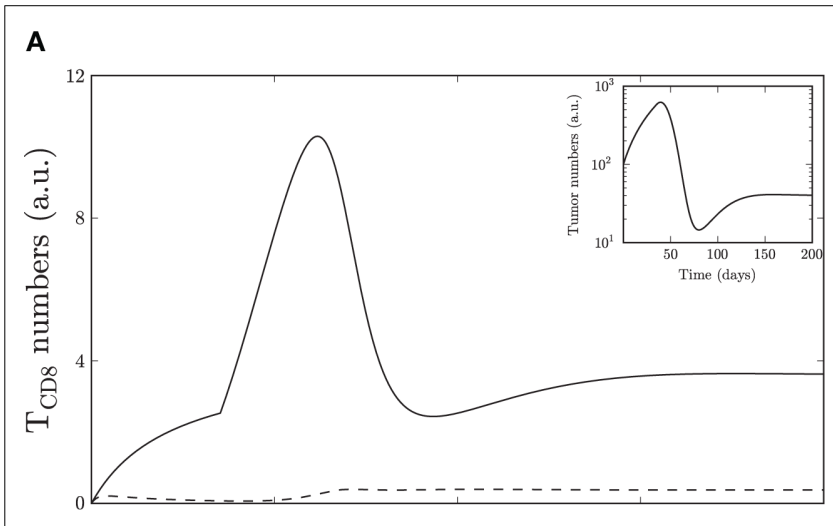

B

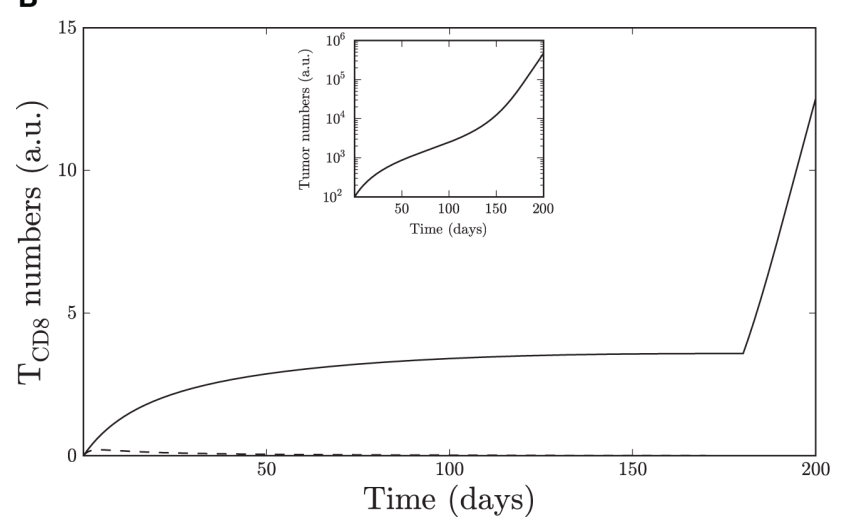

FIGURE 7 | The pancreatic tumor shown in Figure 6 is here modified $(b=3.5, \beta=100)$ and subjected to in silico site IV immunizations of equal strength on $(A)$ day $\mathbf{3 5}$ and $(B)$ day $\mathbf{1 8 0}$. Insets $(A, B)$ show tumor cells on a log scale. Site I-specific $T_{C D 8} S$ is shown with a dashed line and site IV-specific $T_{C D 8} S$ with a solid line ( $T_{|| / / I}$ and $T_{V}$ have negligible values). The early immunization results in a steady state of tumor cells and site IV-specific $T_{C D 8} S$, whereas the later immunization fails to significantly influence tumor growth.

\section{TUMOR CONTROL}

Tumors can be controlled by various immune therapies including immunization with tumor antigen and the adoptive transfer of immune cells (Hersey, 2010; Moschella et al., 2010; van den Broek et al., 2010). To gain insight into the mechanisms of tumor control we simulated a known case of control of pancreatic tumors upon immunization (Otahal et al., 2006). In this study early immunization on day 35 can prevent pancreatic tumor appearance whereas immunization after day 180 cannot prevent tumor formation. Our simulations reproduce this behavior. Simulated immunization leads to a sharp increase in site IV-specific $\mathrm{T}_{\mathrm{CD} 8} \mathrm{~s}$ above the endogenous levels, followed by a decrease that correlates with a drop in tumor cells. Experimentally it is expected that the $\mathrm{T}_{\mathrm{CD} 8}$ response upon immunization surpasses the response generated against the endogenous tumor. Thus the model could simulate the effect of early and late immunization in case of pancreatic tumors.

However, in transgenic mice Tag-expressing cells persist in lower numbers in case of early immunization so that the pancreatic functions are not disrupted. To reproduce this observation the rate of $\mathrm{T}_{\mathrm{CD} 8}$ proliferation, the maximal rate of $\mathrm{T}_{\mathrm{CD} 8}$ mediated 
killing of tumor cells, and the threshold number of tumor cells that inhibit killing have to be increased. After increasing these parameters the dose of immunization could be decreased and the control of tumors with early immunization (Figure 7A) but not late immunization (Figure 7B) was reproduced in the pancreatic tumors (Figure 7, inset). Thus our model suggests that exposure to external antigen in transgenic mice facilitates the detection of tumor cells by $\mathrm{T}_{\mathrm{CD} 8} \mathrm{~s}$ and the immunogenicity of Tag.

\section{DISCUSSION}

The current work sheds light upon mechanisms that determine $\mathrm{T}_{\mathrm{CD} 8}$ tolerance onset and the characteristics leading to the sitespecific $\mathrm{T}_{\mathrm{CD} 8} \mathrm{~s}$ response. Both the dynamic model and the experimental data show that the apoptosis rates of $\mathrm{T}_{\mathrm{CD}} 8$ clones are context dependent and that the response in WT C57BL/6 mice is quantitatively stronger than the response in Tag-transgenic mice. This weaker response in Tag-transgenic mice aids the establishment of tolerance in the presence of progressing tumors. We hypothesize that the weaker response is driven by the immediate encounter of the peripheral T cells to Tag expressed on the tumor leading to undetectable $\mathrm{T}_{\mathrm{CD} 8}$ numbers in the transgenic mice. Figure 3 supports this hypothesis by showing a higher apoptotic population in tumor-bearing mice. In fact, in SV11 mice transferred cells encounter tumor antigen earlier than Tag from the cells used for immunization, suggesting that an early encounter with the endogenous tumor antigen also limits response to the exogenous antigen (Ryan and Schell, 2006). In the case of natural tumors, it is possible that the net growth of $\mathrm{T}_{\mathrm{CD} 8} \mathrm{~s}$ varies over the course of tumor progression. The accumulation of responsive $\mathrm{T}_{\mathrm{CD} 8} \mathrm{~s}$ can be enhanced by using anti-CD40 or anti-CTLA- 4 antibodies (Otahal et al., 2007; Ryan et al., 2008). The tissue-specific differences in the peaks of the $\mathrm{T}_{\mathrm{CD}}$ response will affect the time at which immune therapy will be most effective. Differential expression of negative regulators of the receptors such as PD-L1 and Tim3 ligand within tumors of distinct tissues might lead to tissue-specific apoptosis.

Though $\mathrm{T}_{\mathrm{CD} 8}$ tolerance is often observed, particularly in the setting of cancer or transgene expression, the mechanisms leading to tolerance are not clear. Factors that have received considerable attention are the density of peptide/MHC-I complexes, the affinity of TCR for peptide/MHC complexes and the avidity of the interaction between $\mathrm{T}$ cells and antigen-presenting cells (Abbas et al., 2004). These factors affect the activation of $\mathrm{T}_{\mathrm{CD} 8} \mathrm{~s}$ and their effects on the $\mathrm{T}_{\mathrm{CD} 8}$ response are modeled indirectly by assuming high-dose inhibition, antigen-induced cell death (Kabelitz et al., 1993), and immune suppression. While we also include saturation of $\mathrm{T}_{\mathrm{CD} 8} \mathrm{~s}$ in response to large tumors (Graw and Regoes, 2009), we compare the rate of activation and apoptosis in distinct mice in which tolerance is either observed or not. Although experimentally it is difficult to measure the densities of peptideMHCI complexes and affinities of TCR, our approach allows us to establish relationships between different parameters and test them experimentally. Moreover, our model suggests that the differentiation of naïve $\mathrm{T}$ cells is also affected during tolerance. Various evidence such as the disruption of MHCI-peptide and TCR complex (Nagaraj et al., 2007), $\mathrm{T}_{\mathrm{CD} 8}$ exhaustion (Moskophidis et al., 1993) and tumor-induced $\mathrm{T}_{\mathrm{CD} 8}$ suppressive microenvironment
(Lee et al., 1999; Khong and Restifo, 2002) support the inhibition of the differentiation from naïve T cells during tolerance. Studies of the $\mathrm{T}_{\mathrm{CD} 8}$ response to the Tag determinants suggest that tolerance is related to immunodominance since $\mathrm{T}_{\mathrm{CD} 8}$ specific for the immunorecessive determinant ( site $\mathrm{V}$ ) are the least sensitive to tolerance even in the highly tolerogenic brain tumor model (Schell et al., 2000). In this context, it is interesting that subdominant site I-specific $\mathrm{T}_{\mathrm{CD} 8} \mathrm{~s}$ undergo tolerance earlier than immunodominant site IV-specific $\mathrm{T}_{\mathrm{CD} 8} \mathrm{~s}$, suggesting that higher levels of site $\mathrm{I} / \mathrm{MHC}$ versus site IV/MHC complexes may be achieved in vivo during tumor progression. We assume that the dependence of the $\mathrm{T}$ cell response on the number of tumor cells is described by Michaelis-Menten kinetics which is a commonly used functional form to model saturating response at high doses in biological systems. The support for such behavior comes from observations in chronic infections and cancers which limit the activation of the immune responses even when the antigen is not cleared (Kabelitz et al., 1993; Wigginton and Kirschner, 2001). We note that the Michaelis-Menten function is a special case of a Hill function which may also be a good choice but it has an additional unknown parameter as compared to the Michaelis-Menten function.

Simulations in WT mice suggest that the differential activities of site-specific $\mathrm{T}_{\mathrm{CD} 8} \mathrm{~s}$ are driven by the site-specific rates of apoptosis. The rate of apoptosis was estimated in the contraction phase when Tag-expressing cells are cleared. At earlier time points the percentages observed in the experiments (Figures $3 \mathrm{C}$ and $\mathbf{6 B}$ ) are the outcome of the dynamics modeled by the rate of activation $(n)$, proliferation $(c)$, and apoptosis $\left(w_{i}\right)$. In the absence of experimental estimates the rate constants used in our model represent an average rate of apoptosis over time. Hence we validate modelpredicted inequalities rather than attempting to estimate the exact values of apoptosis rates. Though free decay is a commonly made assumption in dynamic models, antigen concentrations and the duration of antigen exposure can affect the apoptosis rate of the $\mathrm{T}_{\mathrm{CD} 8}$ cells which can be included in a future extension of the current model (Porter and Harty, 2006). On the contrary, the accurate prediction of the rate of proliferation $(c)$ was not possible (Figure 4) due to the sparse data (Trinchieri et al., 1976) and various parameters affecting the expansion phase including $\mathrm{T}_{\mathrm{CD} 8}$ apoptosis $\left(w_{i}\right.$; Figure 5B), differentiation from naïve $\mathrm{T}$ cells $\left(n_{i}\right)$, and the proliferation of $\mathrm{T}_{\mathrm{CD} 8} \mathrm{~s}(c)$. The use of similar proliferation rates for $\mathrm{T}_{\mathrm{CD} 8} \mathrm{~s}$ specific to site I and IV is supported by the experimental data (Figure 5A). We maintain the same rate of proliferation for all site-specific $\mathrm{T}_{\mathrm{CD} 8} \mathrm{~s}$, a simplification which we believe is valid for the dominant sites. The rules may be different for site $\mathrm{V}$ since the addition of more site $\mathrm{V}$-specific precursors does not overcome the weak response to site V (Otahal et al., 2005). However, estimating the true proliferation rate of site $\mathrm{V}$-specific $\mathrm{T}_{\mathrm{CD} 8} \mathrm{~s}$ is challenging since these cells remain below the threshold of detection following immunization of WT mice with Tag. Overall the data support a mechanism in which differences in the rate of apoptosis explain the prolonged high level accumulation of site IV-specific $\mathrm{T}_{\mathrm{CD} 8} \mathrm{~s}$ cells relative to $\mathrm{T}_{\mathrm{CD} 8} \mathrm{~s}$ responding to the subdominant determinants.

The current model is an outcome of a step-wise process to reproduce the $\mathrm{T}_{\mathrm{CD} 8}$ response in $\mathrm{WT}$ and Tag-transgenic mice. 
As a first step we modeled all the immune processes that are hypothesized to be important in $\mathrm{T}_{\mathrm{CD} 8}$ activation. Next, we reduced the model based on what is required to reproduce the known experimental observations, for example separately modeling pMHC complexes on the antigen-presenting cells did not lead to an improvement of the model but increased the number of unknown parameters (Handel and Antia, 2008). We do not explicitly include naïve $\mathrm{T}_{\mathrm{CD} 8} \mathrm{~s}$ in the model, assuming that they are not a rate limiting factor in the tumor-induced $\mathrm{T}$ cell interactions. However, in the biologically accepted range of parameters (Figure A3 in Appendix) the effective value of the rate of differentiation of precursor cells is never unlimited in our model. Many mathematical models have assumed a constant number of precursor cells and in those models estimates of the effective rate of thymic production vary within $25 \%$ of the $n_{i} c$ values used in our model. The mathematical formulations modeling $\mathrm{T}_{\mathrm{CD}}$ response to tumors generally incorporate higher values of the source for $\mathrm{T}_{\mathrm{CD} 8} \mathrm{~s}$ compared to the models of $\mathrm{T}_{\mathrm{CD} 8}$ response to viruses. This could be because the immune response is measured following immunization which usually inflates the response. We also would like to note that the value of the rate of proliferation is also in the range of estimations by other studies (De Boer et al., 2003; Bocharov et al., 2004).

In the current model we did not explore the possibility of introducing competition between $\mathrm{T}_{\mathrm{CD} 8}$ clones because recent results indicate that in WT mice competition between the endogenous $\mathrm{T}_{\mathrm{CD} 8} \mathrm{~s}$ responding to sites I and IV does not play a significant role in limiting the magnitude of the $\mathrm{T}$ cell response (Tatum et al., 2010). We did previously observe that the presence of the dominant Tag determinants can limit the response to site V (Mylin et al., 2000). The absence of a detectable endogenous site Vspecific $\mathrm{T}_{\mathrm{CD} 8}$ response upon immunization with Tag-expressing cells makes it difficult to make assumptions about the interactions between physiological levels of $\mathrm{T}_{\mathrm{CD} 8}$ s specific for dominant and recessive epitopes. Though we cannot rule out the possibility of competitive interactions, non-competitive interactions mediated by weak engagement of TCR with site V-MHCI complexes can also drive the immunorecessive response as modeled in the current study. In conclusion, the mathematical model presented here is one of the few attempts to characterize in vivo $\mathrm{T}_{\mathrm{CD} 8}$ responses to known autochthonous tumors and it systematically analyzes the

\section{REFERENCES}

Abbas, A. K., Lohr, J., Knoechel, B., and Nagabhushanam, V. (2004). $\mathrm{T}$ cell tolerance and autoimmunity. Autoimmun. Rev. 3, 471-475.

Ahuja, D., Saenz-Robles, M. T., and Pipas, J. M. (2005). SV40 large $\mathrm{T}$ antigen targets multiple cellular pathways to elicit cellular transformation. Oncogene 24, 7729-7745.

Antia, R., Ganusov, V. V., and Ahmed, R. (2005). The role of models in understanding CD8+ T-cell memory. Nat. Rev. Immunol. 5, 101-111.
Behboudi, S., Boswell, S., and Williams R. (2010). Cell-mediated immune responses to alpha-fetoprotein and other antigens in hepatocellular carcinoma. Liver Int. 30, 521-526.

Bocharov, G., Ludewig, B., Bertoletti, A., Klenerman, P., Junt, T., Krebs, P., Luzyanina, T., Fraser, C., and Anderson, R. M. (2004). Underwhelming the immune response: effect of slow virus growth on CD8+-Tlymphocyte responses. J. Virol. 78, 2247-2254.

Brinster, R. L., Chen, H. Y., Messing, A., van Dyke, T., Levine, A. J., and Palmiter, R. D. (1984).

expansion and contraction phases during the $\mathrm{T}_{\mathrm{CD} 8}$ response to a known tumor antigen.

In the future, this model could be expanded by including competitive interactions between site-specific clones for different antigens and by separately modeling the reactivation of memory $T$ cells in response to the antigen (Camus and Galon, 2010). Modeling of naïve T cells as a separate entity will also allow us to study the effects of adoptive transfers, which are currently under clinical investigation for several cancer types. One could also incorporate immune cells such as $\mathrm{T}$ regulatory cells which are implicated in inducing tolerance and model the recovery of responsive $\mathrm{T}_{\mathrm{CD} 8}$ cells (Sharabi and Ghera, 2010). Moreover, the case of uncontrolled $\mathrm{T}$ cell and Tag-expressing cell growth is similar to autoimmune response and though it is not a focus of the current study, the model can be used to study the relationship between tumor and autoimmunity since tolerance (Schuetz et al., 2010) and dysregulation of immune responses (Reeves et al., 2009) are implicated in both diseases. While opportunities exist to build on this basic model, relevant in vivo data are needed to inform and parameterize the expansion. Moreover, standardization of experimental techniques will be useful since the observations are not only affected by personal and lab-specific factors but also by the mice strains used. We show here that our model not only provides novel predictions that can be experimentally validated but also gives important insights based on sparse data. Models such as ours will be increasingly developed and used to provide novel predictions and biological understanding of the complex interaction between the immune system and cancer.

\section{ACKNOWLEDGMENTS}

This work was partially funded by research grant R01-CA-025000 from the National Cancer Institute/National Institutes of Health (to Todd D. Schell). We would like to thank Alan M. Watson and Dr. Angela M. Tatum for their advice, Aijun Liao for her assistance with experiments, and Nate Sheaffer and Dr. David Stanford for help with acquisition and analysis of flow cytometry data. Juilee Thakar is thankful to the Cancer Research Institute for a postdoctoral fellowship.

Ethics statement: All animal studies were performed under active protocols approved by the Pennsylvania State University Institutional Animal Care and Use Committee.

Transgenic mice harboring SV40 Tantigen genes develop characteristic brain tumors. Cell 37, 367.

Butel, J. S., and Lednicky J. A. (1999). Cell and molecular biology of simian virus 40: implications for human infections and disease. J. Natl. Cancer Inst. 91, 119-134.

Camus, M., and Galon J. (2010). Memory T-cell responses and survival in human cancer: remember to stay alive. Adv. Exp. Med. Biol. 684, 166-177.

Castiglione, F., and Piccoli B. (2007). Cancer immunotherapy, mathematical modeling and optimal control. J.
Theor. Biol. 247, 723-732.

Colella, T. A., Bullock, T. N., Russell, L. B., Mullins, D. W., Overwijk, W. W., Pierce, R. A., Restifo, N. P., and Engelhard, V. H. (2000). Self-tolerance to the murine homologue of a tyrosinase-derived melanoma antigen: implications for tumor immunotherapy. J. Exp. Med. 191, 1221-1232.

Cordaro, T. A., de Visser, K. E., Tirion, F. H., Schumacher, T. N., and Kruisbeek, A. M. (2002). Can the lowavidity self-specific $\mathrm{T}$ cell repertoire be exploited for tumor rejection? J. Immunol. 168, 651-660. 
Day, J., Rubin, J., Vodovotz, Y., Chow, C. C., Reynolds, A., and Clermont, G. (2006). A reduced mathematical model of the acute inflammatory response. II. Capturing scenarios of repeated endotoxin administration. J. Theor. Biol. 242, 237-256.

De Boer, R. J., Homann, D., and Perelson, A. S. (2003). Different dynamics of $\mathrm{CD} 4+$ and $\mathrm{CD} 8+$ $\mathrm{T}$ cell responses during and after acute lymphocytic choriomeningitis virus infection. J. Immunol. 171, 3928-3935.

de Pillis, L. G., Radunskaya, A. E., and Wiseman, C. L. (2005). A validated mathematical model of cell-mediated immune response to tumor growth. Cancer Res. 65, 7950-7958.

Dunn, G. P., Bruce, A. T., Ikeda, H., Old, L. J., and Schreiber, R. D. (2002). Cancer immunoediting: from immunosurveillance to tumor escape. Nat. Immunol. 3, 991-998.

Faas, S. J., Pan, S., Pinkert, C. A., Brinster, R. L., and Knowles, B. B. (1987). Simian virus 40 (SV40)-transgenic mice that develop tumors are specifically tolerant to SV40 T antigen. J. Exp. Med. 165, 417-427.

Fu, T. M., Mylin, L. M., Schell, T. D., Bacik, I., Russ, G., Yewdell, J. W., Bennink, J. R., and Tevethia, S. S. (1998). An endoplasmic reticulum-targeting signal sequence enhances the immunogenicity of an immunorecessive simian virus 40 large $\mathrm{T}$ antigen cytotoxic $\mathrm{T}$ lymphocyte epitope. J. Virol. 72, 1469-1481.

Fujimura, T., Mahnke, K., and Enk, A. H. (2010). Myeloid derived suppressor cells and their role in tolerance induction in cancer. J. Dermatol. Sci. $59,1-6$.

Gajewski, T. F., Meng, Y., Blank, C., Brown, I., Kacha, A., Kline, J., and Harlin, H. (2006). Immune resistance orchestrated by the tumor microenvironment. Immunol. Rev. 213, 131-145.

Ganss, R., and Hanahan, D. (1998). Tumor microenvironment can restrict the effectiveness of activated antitumor lymphocytes. Cancer Res. 58, 4673-4681.

Graw, F., and Regoes, R. R. (2009). Investigating CTL mediated killing with a 3D cellular automaton. PLoS Comput. Biol. 5, e1000466. doi: 10.1371/journal.pcbi.1000466

Handel, A., and Antia, R. (2008). A simple mathematical model helps to explain the immunodominance of CD8 $\mathrm{T}$ cells in influenza A virus infections. J. Virol. 82, 7768-7772.
Hersey, P. (2010). Immunotherapy of melanoma. Asia Pac. J. Clin. Oncol. 6(Suppl. 1), S2-S8.

Kabelitz, D., Pohl, T., and Pechhold, K. (1993). Activation-induced cell death (apoptosis) of mature peripheral T lymphocytes. Immunol. Today 14, 338-339.

Khong, H. T., and Restifo, N. P. (2002). Natural selection of tumor variants in the generation of "tumor escape" phenotypes. Nat. Immunol. 3, 999-1005.

Kirschner, D., and Panetta, J. C. (1998). Modeling immunotherapy of the tumor-immune interaction. J. Math. Biol. 37, 235-252.

Kirschner, D., and Tsygvintsev, A. (2009). On the global dynamics of a model for tumor immunotherapy. Math. Biosci. Eng. 6, 573-583.

Lee, P. P., Yee, C., Savage, P. A., Fong, L., Brockstedt, D., Weber, J. S., Johnson, D., Swetter, S., Thompson, J., Greenberg, P. D., Roederer, M., and Davis, M. M. (1999). Characterization of circulating $\mathrm{T}$ cells specific for tumor-associated antigens in melanoma patients. Nat. Med. 5, 677-685.

Mallet, D. G., and De Pillis, L. G. (2006). A cellular automata model of tumor-immune system interactions. J. Theor. Biol. 239, 334-350.

Morgan, D. J., Kreuwel, H. T., Fleck, S., Levitsky, H. I., Pardoll, D. M., and Sherman, L. A. (1998). Activation of low avidity CTL specific for a self epitope results in tumor rejection but not autoimmunity. J. Immunol. 160, 643-651.

Moschella, F., Proietti, E., Capone, I., and Belardelli, F. (2010). Combination strategies for enhancing the efficacy of immunotherapy in cancer patients. Ann. N. Y. Acad. Sci. 1194, 169-178.

Moskophidis, D., Lechner, F., Pircher, H., and Zinkernagel, R. M. (1993). Virus persistence in acutely infected immunocompetent mice by exhaustion of antiviral cytotoxic effector T cells. Nature 362, 758-761.

Mylin, L. M., Schell, T. D., Roberts, D., Epler, M., Boesteanu, A., Collins, E. J., Frelinger, J. A., Joyce, S., and Tevethia, S. S. (2000). Quantitation of CD8(+) T-lymphocyte responses to multiple epitopes from simian virus 40 (SV40) large $\mathrm{T}$ antigen in $\mathrm{C} 57 \mathrm{BL} / 6$ mice immunized with SV40, SV40 T-antigen-transformed cells, or vaccinia virus recombinants expressing full-length $\mathrm{T}$ antigen or epitope minigenes. J. Virol. 74, 6922-6934.

Nagaraj, S., Gupta, K., Pisarev, V., Kinarsky, L., Sherman, S., Kang, L., Herber, D. L., Schneck, J., and Gabrilovich, D. I. (2007). Altered recognition of antigen is a mechanism of CD8 $+\mathrm{T}$ cell tolerance in cancer. Nat. Med. 13, 828-835.

Nugent, C. T., Morgan, D. J., Biggs, J. A., Ko, A., Pilip, I. M., Pamer, E. G., and Sherman, L. A. (2000). Characterization of CD8 $+\mathrm{T}$ lymphocytes that persist after peripheral tolerance to a self antigen expressed in the pancreas. J. Immunol. 164, 191-200.

Otahal, P., Hutchinson, S. C., Mylin, L. M., Tevethia, M. J., Tevethia, S. S. and Schell, T. D. (2005). Inefficient cross-presentation limits the CD8+ $\mathrm{T}$ cell response to a subdominant tumor antigen epitope. J. Immunol. $175,700-712$.

Otahal, P., Knowles, B. B., Tevethia, S. S., and Schell, T. D. (2007). Anti-CD40 conditioning enhances the $\mathrm{T}(\mathrm{CD} 8)$ response to a highly tolerogenic epitope and subsequent immunotherapy of simian virus $40 \mathrm{~T}$ antigen-induced pancreatic tumors. J. Immunol. 179, 6686-6695.

Otahal, P., Schell, T. D., Hutchinson, S. C., Knowles, B. B., and Tevethia, S. S. (2006). Early immunization induces persistent tumor-infiltrating CD8+ $\mathrm{T}$ cells against an immunodominant epitope and promotes lifelong control of pancreatic tumor progression in SV40 tumor antigen transgenic mice. J. Immunol. 177, 3089-3099.

Patel, S., and Chiplunkar S. (2009). Host immune responses to cervical cancer. Curr. Opin. Obstet. Gynecol. 21, 54-59.

Porter, B. B., and Harty J. T. (2006). The onset of CD8+-T-cell contraction is influenced by the peak of Listeria monocytogenes infection and antigen display. Infect. Immun. 74, 1528-1536.

Pretell, J., Greenfield, R. S., and Tevethia, S. S. (1979). Biology of simian virus 40 (SV40) transplantation antigen (TrAg). V. In vitro demonstration of SV40 TrAg in SV40 infected nonpermissive mouse cells by the lymphocyte mediated cytotoxicity assay. Virology 97, 32-41.

Qin, Z., and Blankenstein T. (2000). $\mathrm{CD} 4+\mathrm{T}$ cell-mediated tumor rejection involves inhibition of angiogenesis that is dependent on IFN gamma receptor expression by nonhematopoietic cells. Immunity 12, 677-686.

Reeves, W. H., Lee, P. Y., Weinstein, J. S., Satoh, M., and Lu, L. (2009). Induction of autoimmunity by pristane and other naturally occurring hydrocarbons. Trends Immunol. 30, 455-464.

Ryan, C. M., and Schell T. D. (2006). Accumulation of CD8+ $\mathrm{T}$ cells in advanced-stage tumors and delay of disease progression following secondary immunization against an immunorecessive epitope. J. Immunol. 177, 255-267.

Ryan, C. M., Staveley-O'Carroll, K., and Schell, T. D. (2008). Combined anti-CD40 conditioning and well-timed immunization prolongs CD8+ T cell accumulation and control of established brain tumors. J. Immunother. 31, 906-920.

Schell, T. D., Knowles, B. B., and Tevethia, S. S. (2000). Sequential loss of cytotoxic T lymphocyte responses to simian virus 40 large $\mathrm{T}$ antigen epitopes in $\mathrm{T}$ antigen transgenic mice developing osteosarcomas. Cancer Res. 60, 3002-3012.

Schell, T. D., Mylin, L. M., Georgoff, I., Teresky, A. K., Levine, A. J., and Tevethia, S. S. (1999). Cytotoxic T-lymphocyte epitope immunodominance in the control of choroid plexus tumors in simian virus 40 large $\mathrm{T}$ antigen transgenic mice. J. Virol. 73, 5981-5993.

Schreiber, R. D., Old, L. J., Hayday, A. C., and Smyth, M. J. (2004). A cancer immunosurveillance controversy. Nat. Immunol. 5, 4-5.

Schuetz, C., Niehues, T., Friedrich, W., and Schwarz, K. (2010). Autoimmunity, autoinflammation and lymphoma in combined immunodeficiency (CID). Autoimmun. Rev. 9, 477-482.

Sharabi, A., and Ghera N. H. (2010). Breaking tolerance in a mouse model of multiple myeloma by chemoimmunotherapy. Adv. Cancer Res. 107, 1-37.

Tanaka, Y., Anderson, R. W., Maloy, W. L., and Tevethia, S. S. (1989). Localization of an immunorecessive epitope on SV40 T antigen by H-2Dbrestricted cytotoxic T-lymphocyte clones and a synthetic peptide. Virology 171, 205-213.

Tatum, A. M., Mylin, L. M., Bender S. J., Fischer, M. A., Vigliotti, B. A., Tevethia, M. J., Tevethia, S. S., and Schell, T. D. (2008). CD8+ T cells targeting a single immunodominant epitope are sufficient for elimination of established SV40 T antigeninduced brain tumors. J. Immunol. 181, 4406-4417.

Tatum, A. M., Watson, A. M., and Schell, T. D. (2010). Direct presentation regulates the magnitude of the CD8+ $\mathrm{T}$ cell response to cell-associated antigen through prolonged $\mathrm{T}$ cell proliferation. J. Immunol. 185, 2763-2772.

Tevethia, S. S., Greenfield, R. S., Flyer, D. C., and Tevethia, M. J. (1980). SV40 transplantation antigen: relationship to SV40-specific proteins. Cold Spring Harb. Symp. Quant. Biol. 44(Pt. 1), 235-242. 
Tevethia, S. S., and Schell T. D. (2001). "The immune response to SV40, JCV and BKV," in Human Polyomaviruses: Molecular and Clinical Perspectives, eds K. Khalili and G. L. Stoner (New York: Wiley), 585-610.

Theobald, M., Biggs, J., Hernández, J., Lustgarten, J., Labadie, C., and Sherman, L. A. (1997). Tolerance to $\mathrm{p} 53$ by A2.1-restricted cytotoxic T lymphocytes. J. Exp. Med. 185, 833-841.

Trinchieri, G., Aden, D. P., and Knowles, B. B. (1976). Cell-mediated cytotoxicity to SV40-specific tumourassociated antigens. Nature 261, 312-314.

van den Broek, M., von Boehmer, L., and Knuth, A. (2010). Developments in cancer immunotherapy. Dig. Dis. 28, 51-56.
Wigginton, J. E., and Kirschner D. (2001). A model to predict cell-mediated immune regulatory mechanisms during human infection with Mycobacterium tuberculosis. J. Immunol. 166, 1951-1967.

Xu, Q., Liu, G., Yuan, X., Xu, M., Wang, H., Ji, J., Konda, B., Black, K. L., Yu, J. S. (2009). Antigen-specific T-cell response from dendritic cell vaccination using cancer stem-like cellassociated antigens. Stem Cells 27, 1734-1740.

Ye, X., McCarrick, J., Jewett, L., and Knowles, B. B. (1994). Timely immunization subverts the development of peripheral nonresponsiveness and suppresses tumor development in simian virus 40 tumor antigen-transgenic mice.
Proc. Natl. Acad. Sci. U.S.A. 91, 3916-3920.

Zheng, X., Gao, J. X., Zhang, H., Geiger, T. L., Liu, Y., and Zheng, P. (2002). Clonal deletion of simian virus 40 large $\mathrm{T}$ antigen-specific $\mathrm{T}$ cells in the transgenic adenocarcinoma of mouse prostate mice: an important role for clonal deletion in shaping the repertoire of $\mathrm{T}$ cells specific for antigens overexpressed in solid tumors. J. Immunol. 169, 4761-4769.

Conflict of Interest Statement: The authors declare that the research was conducted in the absence of any commercial or financial relationships that could be construed as a potential conflict of interest.
Received: 23 March 2011; accepted: 18 June 2011; published online: 11 July 2011. Citation: Campbell C, Zhang R, Haley $J S$, Liu X, Loughran T, Schell TD, Albert $R$ and Thakar J (2011) Why do CD8+ $T$ cells become indifferent to tumors: a dynamic modeling approach. Front. Physio. 2:32. doi: 10.3389/fphys.2011.00032

This article was submitted to Frontiers in Systems Physiology, a specialty of Frontiers in Physiology.

Copyright (c) 2011 Campbell, Zhang, Haley, Liu, Loughran, Schell, Albert and Thakar. This is an open-access article subject to a non-exclusive license between the authors and Frontiers Media SA, which permits use, distribution and reproduction in other forums, provided the original authors and source are credited and other Frontiers conditions are complied with. 


\section{APPENDIX \\ THE EFFECT OF VARIATION OF THE PARAMETERS ON THE RATE OF KILLING OF TUMOR CELLS BY $\mathrm{T}_{\text {CD8 }} \mathrm{S}$ \\ Nullcline Analysis}

In this section we elaborate upon the biologically relevant dynamical regimes exhibited by the model. While we show the evolution of the number of tumor cells and $\mathrm{T}_{\mathrm{CD} 8}$ cells as a function of time in Figure A2, we here show the two variables plotted against one another. This method allows for straightforward identification of the system dynamics for any possible number of $\mathrm{T}_{\mathrm{CD} 8} \mathrm{~s}$ and tumor cells.

The directional field, which is represented by gray arrows in the lower panels of Figure A2, indicates the evolution of tumor cells and $\mathrm{T}_{\mathrm{CD} 8} \mathrm{~s}$ with time. For instance, when the number of tumor cells and $\mathrm{T}_{\mathrm{CD} 8} \mathrm{~s}$ are in an area of phase space where the directional field is increasing in both dimensions, the number of Tag-expressing cells and $\mathrm{T}_{\mathrm{CD} 8} \mathrm{~s}$ cells will both increase for a small advancement in time, and their next position in phase space will decide the change in both variables for the next advancement in time. The trajectory is shown by the solid black line. Broken black lines show the boundary between areas in phase space that are increasing or decreasing with respect to $\mathrm{T}_{\mathrm{CD} 8} \mathrm{~s}$ (dash-dotted line) or tumor cells (dashed line). The intersection of nullclines corresponds to steady states of the system. Zero tumor cells and $\mathrm{T}_{\mathrm{CD} 8} \mathrm{~s}$ is always a steady state; for the parameters investigated here, the nullclines typically admit at most one additional steady state (see main text for the mathematical form of the nullclines).

The clearance scenario (Figure A2A) shows the system's starting point in a location where the directional field is increasing in both dimensions. The trajectory crosses the tumor cell nullcline, whereupon the number of tumor cells begins decreasing. Once it drops below the $\mathrm{T}_{\mathrm{CD} 8}$ nullcline, the number of $\mathrm{T}_{\mathrm{CD} 8} \mathrm{~s}$ also begins decreasing; the system eventually reaches a steady state

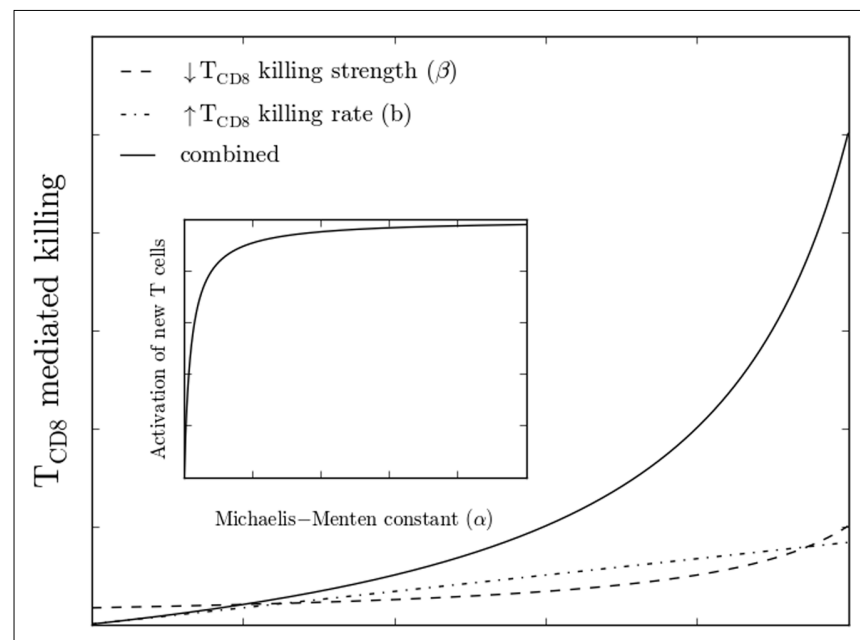

Parameter Values

FIGURE A1 | The effect of the variation in the rate constant and the number of tumor cells on the $\mathrm{T}_{\mathrm{CD}}$ mediated killing of Tag-expressing cells. The inset shows the effect of tumor cell numbers on the activation of $\mathrm{T}_{\mathrm{CD} 8} \mathrm{~S}$. located very close to 0 tumor cells and $\mathrm{T}_{\mathrm{CD} 8} \mathrm{~s}$. The different parameters used in Figures 2B-E alter the properties of the directional field and nullclines, and so influence the evolution of the system despite the fact that they start in the same location in phase space.

\section{Parameter values and their sensitivity}

There are a maximum of 18 parameters in the model. For simplicity the parameters are assumed to have the same value in different tissues in the absence of tissue-specific information to constrain the values. However, site-specific apoptosis rates were implemented to reproduce the different onset times of tolerance of site-specific $\mathrm{T}_{\mathrm{CD} 8} \mathrm{~s}$. To study the effect of parameters we systematically varied the parameter values from 50 to $200 \%$ of their initial values [i.e., $\left.p_{i}=k p_{0}, k \in(0.5,2)\right]$. We calculated the percent deviation due to a given parameter modification for variable $V$ at time $\tau$ as

$d_{v(t=\tau)}=\left|\frac{V\left(p=p_{0}, t=\tau\right)-V\left(p=p_{i}, t=\tau\right)}{V\left(p=p_{0}, t=\tau\right)}\right|$

Averaging over all time points gives an average percent deviation (APD) for variable $V$ and deviation $k$ for parameter $p$.

In the model, the peak of the $\mathrm{T}_{\mathrm{CD} 8}$ accumulation corresponds to the system crossing the $\mathrm{T}_{\mathrm{CD} 8}$ nullcline in phase space (see main text). The main parameters that drive the response of the $\mathrm{T}_{\mathrm{CD} 8} \mathrm{~s}$ are $c$ and $w_{i}$. We modify these parameters and quantify the difference of the ensuing dynamics from the original via an APD. There are a maximum of 18 parameters in the model and the parameters are assumed to have the same value in different tissues for simplicity in the absence of tissue-specific information to constrain the values. However, site-specific activation of naïve cells and apoptosis rates were implemented to reproduce the onset times of tolerance. To study the effect of parameters we systematically varied the parameter values from 50 to $200 \%$ of their initial values (i.e., $p_{i}=k p_{0}$, $k \in(0.5,2))$. We calculated the percent deviation due to a given parameter modification for variable $V$ at time $\tau$ as

$d_{v(t=\tau)}=\left|\frac{V\left(p=p_{0}, t=\tau\right)-V\left(p=p_{i}, t=\tau\right)}{V\left(p=p_{0}, t=\tau\right)}\right|$

Averaging over all time points gives an APD for variable $V$ and deviation $k$ for parameter $p$.

This measure identifies at a glance the sensitivity of the system to variations in particular parameters. We show as an illustrative example the APDs for the pancreatic, osteosarcoma, and WT cases (Figures A3B-D). Reducing $w_{I V}$ in a tumor case serves to bolster the immune response; $T_{\text {IV }}$ effectively chases after IC more vigorously before giving up, until eventually it is able to clear the tumor entirely. In the pancreatic case (Figure A3B), w is not decreased enough to show the regime clearance. In the osteosarcoma case, the full transition is seen. In the case of brain tumors, $T_{\text {IV }}$ plays a minimal role; varying $w_{\text {IV }}$ has comparatively little effect on the system dynamics. 

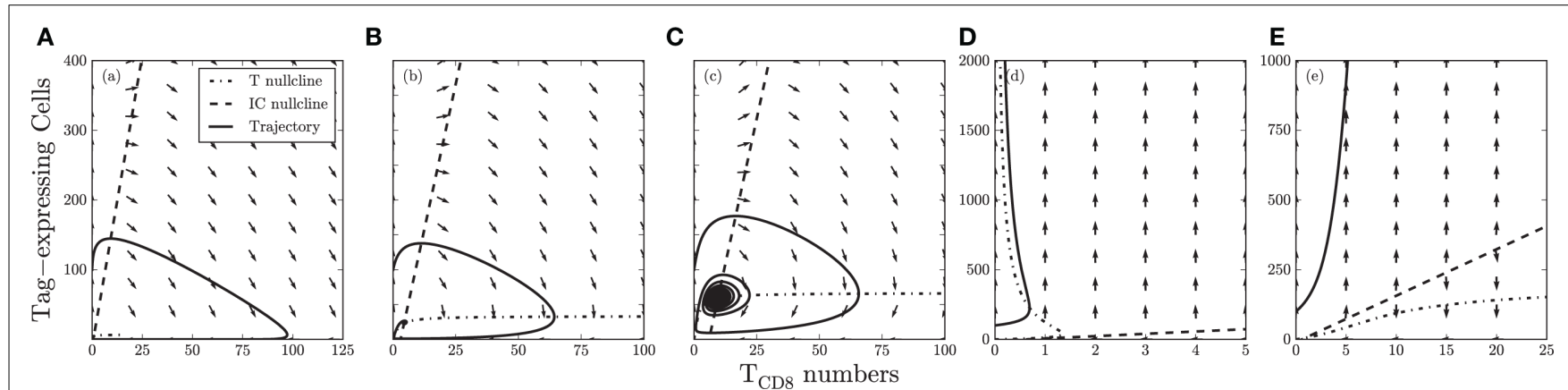

FIGURE A2 | The behaviors from Figure A1 are shown in phase space. Light gray arrows indicate the directional field, and the nullclines indicate boundaries between positive and negative horizontal or vertical components of the directional field. Intersections of the nullclines indicate steady states of the system.
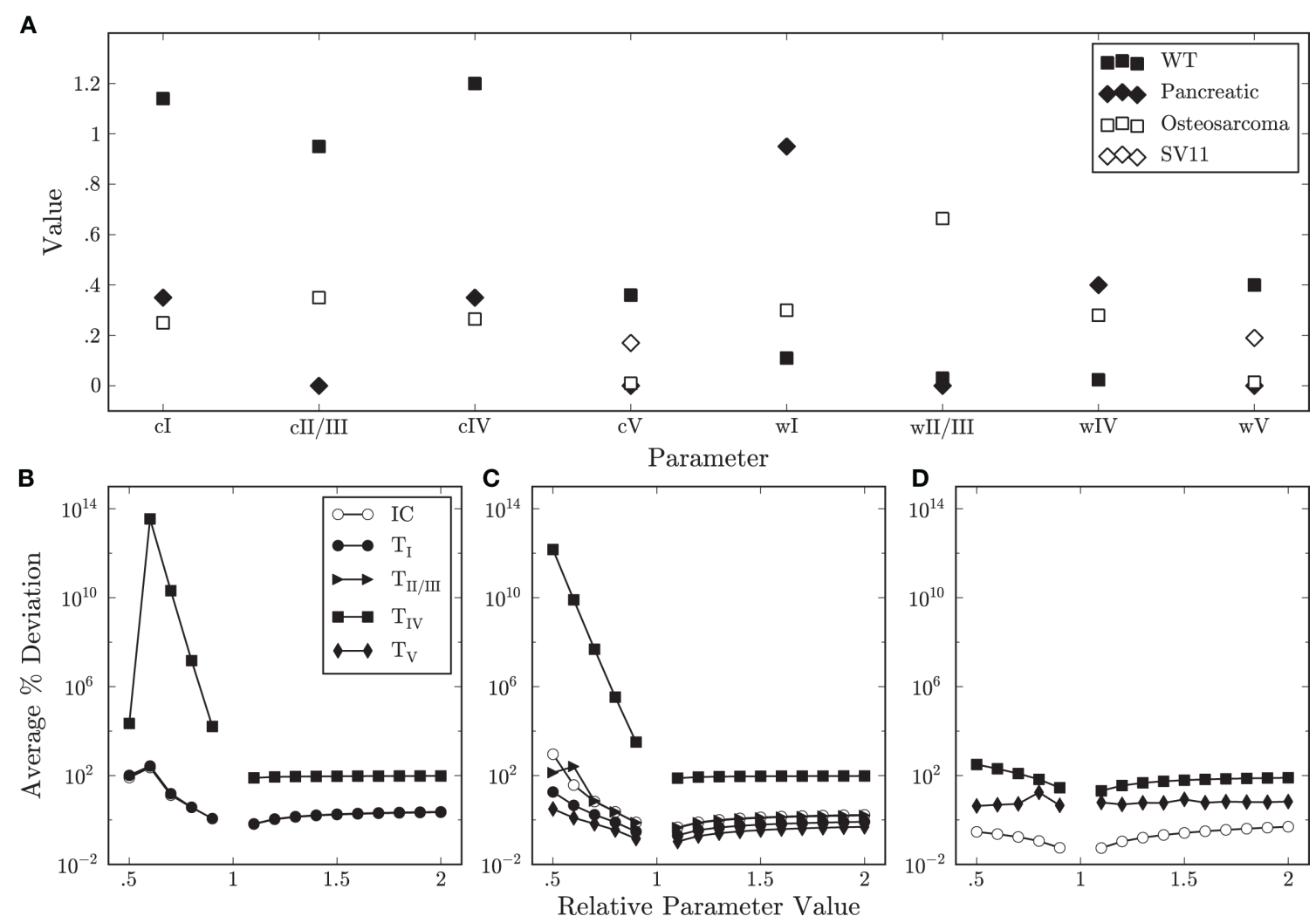

FIGURE A3 | (A) The values of the parameters that were varied in different cases are shown on the $x$-axis for the wild-type (black squares), pancreatic tumor (black diamonds), osteosarcoma (white squares), and brain tumor (white diamonds) models. $n_{1}$ fixes the value of $n_{1 \mathrm{~V}}\left(=4 n_{1}\right)$ and $n_{\mathrm{V}}\left(=0.3 n_{1}\right)$, and are not shown. (B-D) The effect of varying the $w_{\mathrm{IV}}$ parameters by a multiplicative factor ( $x$-axes) on the variables is shown as an average percent deviation (APD) in the pancreatic, osteosarcoma, and wild-type cases $\left(y\right.$-axes). Very small APDs $\left(<10^{-9}\right)$ are not shown. 